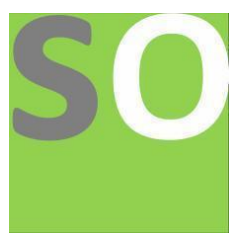

Article title: La educación no formal y la destrucción de la identidad nacional peruana durante la ocupación de Tacna y Arica: "El Escultismo en la Chilenización de Tacna y Arica". *

The no formal education how to

mechanism of deconstruction of Peruvian identity in to Tacna and Arica captivity: "The scouting at Chileanization process to Tacna y Arica".

Authors: Gary Martín Osorio Soto[1]

Affiliations: Asociación de Estudios Históricos de Tacna - AEHT[1]

Orcid ids: $0000-0002-9629-487 \times[1]$

Contact e-mail: martinosorio302@gmail.com

License information: This work has been published open access under Creative Commons Attribution License http://creativecommons.org/licenses/by/4.0/, which permits unrestricted use, distribution, and reproduction in any medium, provided the original work is properly cited. Conditions, terms of use and publishing policy can be found at https://www.scienceopen.com/.

Preprint statement: This article is a preprint and has not been peer-reviewed, under consideration and submitted to ScienceOpen Preprints for open peer review.

DOI: 10.14293/S2199-1006.1.SOR-.PP879BI.v1

Preprint first posted online: 23 March 2021

Keywords: Chilenización, Cautiverio, Movimiento Scout, Tacna y Arica, Perú, Chile, Resistencia, Educación 


\title{
La educación no formal y la destrucción de la identidad nacional peruana durante la ocupación de Tacna y Arica: "El Escultismo en la Chilenización de Tacna y Arica". *
}

The no formal education how to mechanism of deconstruction of Peruvian identity in to Tacna and Arica captivity: "The scouting at Chileanization process to Tacna y Arica".

\author{
Gary Martín Osorio Soto \\ Universidad Europea del Atlántico \\ Asociación de Estudios Históricos de Tacna - AEHT \\ martinosorios302@gmail.com, \\ ORCID https://orcid.org/0000-0002-9629-487X
}

\begin{abstract}
The present article it's a historical and documentary review of the application of an alternative education system by means of to the Scouting as a mechanism of Chileanization to children and adolescents Tacna and Arica during the captivity process in to 1900-1929. The use of the scout movement by the Government of Chile during 1900 - 1929, was a fundamental axis of awareness of a "new identity" homeland to the citizens of the captive cities of Tacna and Arica, in addition to the implementation of conscription and identity in the territories of the province of Tarapacá. Chile's internal educational policy was related to the implementation of a policy of military indoctrination from the school, promoting patriotic discourse and military activity from the school. The scout movement was supported to Chilean government to use of patriotic discourse, in the educational context, promoted an action of repression against the Peruvian community in the territories occupied in the war of 1879 '. The civic-military indoctrination, as the ideological arm of the Chilean policy of "Chilenización", was also used by the young people of Tacna and Arica. This process as called "the violent Chileanization".
\end{abstract}

Keywords: Tacna y Arica, Chileanization, Resistance, Captivity; Education, Alternative Education; Nationalism; Motherland Identity; Conflict; War Perú-Chile.

\section{Resumen}

El presente artículo, es una revisión histórica - documental de cómo se aplicación sistemas de educación alternativa por medio del Movimiento Scout como mecanismo de chilenización y resistencia de los niños y adolescentes Tacna y Arica durante el cautiverio 1900-1929. El uso del movimiento scout por parte del Gobierno de Chile durante 1900 - 1929, fue un eje fundamental de concienciación de una "nueva identidad" patria a los ciudadanos de las ciudades cautivas de Tacna y Arica, además de la implementación de conscripción e identidad en los territorios de la provincia de Tarapacá. La política interna de Chile, en materia educativa, estuvo relacionada a la implementación de una política de adoctrinamiento militar desde el colegio, fomentando el discurso patriótico y la actividad militar desde la escuela. El método Scout dio soporte al uso del discurso patriótico, en el contexto educativo fomentó una acción de represión a la comunidad peruana en los territorios ocupados después de la guerra del 1879'. El adoctrinamiento cívico - militar, como brazo ideológico de la política chilena de "Chilenización" utilizado contra los niños y jóvenes de Tacna y Arica fue parte del proceso llamado "Chilenización violenta”.

Palabras clave: Tacna y Arica, Chilenización, Resistencia, Cautiverio; Educación Alternativa; Nacionalismo; Identidad Patria; Conflicto; Guerra Perú-Chile. 


\section{INTRODUCCIÓN}

El Movimiento Scout, fue el sistema de educación no formal más popular en el siglo XIX, el cual fue creado por el Militar Ingles Lord Robert Stevenson Smith Baden Powell en 1907, a consecuencia de su experiencia de uso de los adolescentes durante el conflicto denominado "Las Guerras Boers" en el sitio de Mafeking. En el cual, se estableció un programa educativo - formativo de los jóvenes para la ayuda de las actividades de servicio y socorro al ejercito ingles durante el sitio de Mafeking. En Chile; la estructura cívico - militar del presidente Pedro Montt, vio en el Escultismo y el método Scout, una forma adecuada de formación de los niños y jóvenes dentro del territorio de Chile; lo cual, incluía los territorios ocupados en la Guerra de 1879 y los que aún se encontraban en disputa: Tacna y Arica. Los principales promotores de la formación del Movimiento Scout en Chile, fueron oficiales ex - combatientes de la guerra del 79', entre ellos, el Tnte. Crnel. Enrique Phillips - vencedor de la batalla del Alto de la Alianza acontecida el 26 de mayo de 1880, en la cual, la ciudad de Tacna y la Batalla de Arica el 07 de junio de 1880, las cuales tras su caída quedaron en poder de Chile hasta el año 1929. La estructura dirigencial de Chile, que estaba compuesta por oligarcas con intereses salitreros, políticos, dueños de medios de comunicación, clericales y militares ex combatientes de la Guerra del "Guano y el Salitre". Por tanto, vieron la necesidad de fortalecer la "educación nacionalista" a nivel de todo el ámbito jurisdiccional del gobierno de Chile bajo la consigna de "Por la razón o la fuerza" y las Glorias Militares de la guerra del 79'. En este contexto político - social, es que Chile con el apoyo de las fuerzas políticas nacionalistas y militares fortalecen y promueven la creación del Movimiento Scout en Chile el 26 de marzo de 1909. Por su parte el Perú, se encontraba en una fragilidad económica, política, social y militar posterior a la firma del Tratado de Ancón realizado el 20 de octubre de 1883, mediante el cual, el Perú cedía de forma permanente el departamento salitrero de Tarapacá y dejaba en plebiscito las ciudades de Tacna y Arica por un periodo de diez años, plazo el cual Chile de mutuo propio no cumplió. El gobierno peruano posterior al Tratado de Ancón, se encontraba en un periodo de reconstrucción, por lo cual, no garantizaba, ni aseguraba el mantenimiento de su presencia político-nacional en los territorios ocupados. Sin embargo, entre 1880 - 1900 las escuelas peruanas fueron cerradas mediante la Ley de "Instrucción Pública de Chile" (1868). Hasta 1900, el funcionamiento de las escuelas peruanas era permitido por la junta militar de administración de los territorios ocupados, bajo la doctrina educativa del gobierno del Perú. De allí en adelante la persecución, hostigamiento y hasta desapariciones de ciudadanos peruanos se hizo "pan de cada día" y el adoctrinamiento nacionalista - militar mediante la implementación del Escultismo a los niños y adolescentes de las provincias cautivas. Lo que degeneró en la formación de las "escuelas clandestinas" de resistencia patriótica.

\section{OBJETIVO}

El objetivo principal de la investigación es determinar cómo los procesos de educación no formal mediante la aplicación del método Scout - fueron implementados en las provincias cautivas de Tacna y Arica (1900 - 1929) como mecanismo de adoctrinamiento e implantación de la identidad nacionalista chilena y persecución de la población peruana que deseaba mantener su identidad nacional posterior a la Guerra de 1879.

\section{DESARROLLO DE LA INVESTIGACIÓN}

Para (Pizarro, 2003) los mitos y la construcción de la identidad nacional en el caso de Chile, son parte de la imposición hegemónica de una clase oligarca - empresarial que utilizó los sistemas educativos a disposición de la construcción de la identidad nacional - para Chile - mediante el ensalzamiento de personajes históricos y el concepto de "Fuerza y progreso" por medio de "La razón o la fuerza". Bajo esta estructura argumental, Chile, construyó su identidad nacional.

Autores como (Llanos, 2018) y (PORTOCARRERO \& KOMADIMA, 2001), indican que el Perú cuenta con una identidad nacional fragmentada, estratificada en los procesos histórico-temporales que no terminan de cuajar. La identidad peruana tiene al indígena reivindicacioncita, el cual, pone en auge - en palabras de este grupo - el pasado glorioso del imperio Inca. Por otro lado, los hispanistas que consideran la influencia ibérica y la construcción del Virreinato del Perú como el auge económico- cultural del Perú; y también los

\footnotetext{
${ }^{1}$ Decreto 2271 - Gobierno de Chile del 08 de septiembre de 1920. Documento que oficializa el lema" Por la razón o por la fuerza" en el escudo nacional de Chile. El lema, se usó por primera vez en 1834 en el contexto del proceso llamado "La Patria Nueva". Y la cual, tenía un contexto con los problemas limítrofes de Chile en la cuenca del océano Pacifico.
} 
independentistas, que crearon en la figura de Tupac Amaru II un ejemplo de virtud - que condice con las motivaciones reales - de reivindicación indígena en la nueva patria; y la más próxima a la real identidad nacional peruana, la cual, se dio de forma breve con la muerte de Grau y Bolognesi durante la Guerra del Pacifico. En este proceso del imaginario de la identidad nacional peruana, se forjó un fuerte sentimiento patriótico, sobre todo en las provincias de Tarapacá, Arica y Tacna. Sentimiento, el cual, se forjó antes de la construcción del Perú como república, que perduró hasta pasado el conflicto con Chile y la perdida de los territorios de Tarapacá y Arica.

\section{RESULTADOS}

\subsection{El Movimiento Scout y su expansión por América Latina:}

El éxito de "Escultismo para Muchachos" (BADEN POWEL OF GILWEL, 1908), produjo que el movimiento Scout y la metodología educativa no formal del Escultismo, se expandiera rápidamente por el mundo, por lo que, adoptó el nombre del movimiento de los Boy Scouts. Las tensiones pre bélicas a nivel a mundial y las masificaciones de la educación formativa de los jóvenes, promovió, que muchos gobiernos a nivel mundial, se interesaran en la Metodología Educativa Scout, por los resultados vistos en el Sitio de Mafeking (Guerra contra los Boers) y el campamento de Isla Browsea (Reino Unido). Ya, para 1909 "Escultismo para Muchachos" se había traducido a cinco idiomas, y una reunión Scout en Londres atrajo a más de 11,000 Scouts. Como resultado de unas vacaciones de Baden-Powell en Sur América, Chile fue uno de los primeros países en el mundo en adoptar el sistema propuesto por Baden - Powell.

\subsection{El Escultismo en chile}

Para (Serra Anguita, 2015) quien establece que en el periodo entre 1904 y 1910, Chile, vivía una compleja crisis social, generada por la disrupción en las relaciones entre la clase política dirigente y la población. Como consecuencia de la Guerra del 79', Chile, había ganado territorios altamente ricos en recursos naturales como el salitre. Lo que permitió, el mejoramiento económico de la clase capitalista de Chile. Sin embargo, las condiciones de desigualdad se acrecentaron. El resultado de la guerra del 79', fue una masa desmovilizada conscripta pobre y olvidada, que durante la campaña entre 1879 a 1883, había conseguido "botines de guerra", mediante el uso de la violencia contra las poblaciones civiles peruanas y bolivianas. Esta masa social, al encontrarse en la indigencia a su retorno a Chile, promovió el uso de violencia para subsistir, siendo reprimidos por sus antiguos oficiales y compañeros de armas. La violencia y la miseria de los ex combatientes trajo como consecuencia el inicio del movimiento obrero en las salitreras ocupadas por Chile como resultado de la guerra. Este complejo escenario social, era distinto a lo que reflejaba la clase oligárquica y dirigente de Chile. Las cuales, se vieron altamente favorecidas por las victorias militares. Por lo que los gobiernos de Balmaceda ${ }^{2}$, Montt Álvarez ${ }^{3}$, Riesco Errazuriz ${ }^{4}$ y Pedro Montt Montt ${ }^{5}$, establecieron una política de fomento de la identidad patriótica y construcción de la identidad nacional de Chile. La mejora económica del estado chileno a causa del salitre, generó que su fuerza armada y sistemas ideológico - político se base bajo el ideario de "País vencedor y conquistador" cuya superioridad se basaba en la "superioridad de la raza chilena". Este discurso, tenía que interiorizarse en los nuevos ciudadanos mediante el uso de una educación ideológica- patriótica. Chile, Perú y Bolivia, aun se encontraban con temas pendientes sobre la delimitación de sus fronteras como consecuencia del Tratado de Ancón ${ }^{6}$, entre las cuales estaba pendiente la situación de Tacna y Arica.

En el año 1909, el presidente Pedro Montt Montt, solicita al Teniente Coronel Enrique Phillips, Alcibíades Vicencio y Joaquín Cabezas, se entrevisten con Baden Powell, para coordinar una reunión y exposición con Pedro Montt, entre otros altos funcionarios de gobierno. La reunión se desarrolla el 26 de marzo de 1909 en la Universidad de Chile (ROJAS FLORES J. , 2006).

\footnotetext{
${ }^{2}$ Balmaceda, José Manuel. Presidente de Chile (1886-1891).

${ }^{3}$ Montt Álvarez, Jorge. Presidente de Chile (1891-1896).

${ }^{4}$ Riesco Errázuriz, Germán. Presidente de Chile (1901-1906).

${ }^{5}$ Montt Montt, Pedro. Presidente de Chile (1906-1910).

${ }^{6}$ Tratado de Ancón: 20 de octubre de 1883 - Lima/ Tratado de Paz, amistad y Limite entre Perú y Chile, que ponía fin a la Guerra del Pacifico.
} 


\subsubsection{El Rol de Enrique Phillips}

Enrique Phillips fue jefe y Academia de Guerra del Ejército. Durante la Guerra del Pacifico cumplió el cargo subteniente en el batallón movilizado Rengo el 13 de marzo de 1880. En Tacna, el 26 de mayo de 1880, partición de la batalla del Campo de la Alianza o Batalla del Alto de la Alianza. El 07 de junio de 1880 participa en la Batalla y toma del Morro de Arica. En 1900, Phillips fue designado como parte de la jefatura política - militar para la construcción de la cripta de los caídos en la Batalla de Tacna o Campo de la Alianza, Phillips, fue designado por su condición de jefe de la Academia de Historia del Ejército de Chile. Tacna, aun se encontraba bajo ocupación del gobierno y ejército de Chile, en el periodo denominado la "Chilenización pacífica". Sin embargo, la estrategia chilena entre 1880-1884, periodo en el cual Phillips partición de la Jefatura Política - Militar de la provincia de Tacna y Arica; entendió que, si bien la convivencia era pacífica y armónica, en primer término, no forjaba datos identitarios con los pobladores de Tacna y Arica; quienes aún se sentían peruanos y promovían en las escuelas peruanas de los territorios ocupados la identidad patria peruana. Chile, entre los años 1887-1915, ejecuta ingentes cantidades de dinero en las provincias cautivas, en obras de infraestructura pública, entre ellas escuelas. Remitiendo de la capital chilena, los mejores pedagogos de la época. En las provincias cautivas del Perú, la educación era bilingüe y de alta calidad, en comparación a otras ciudades de Chile. Sin embargo, los esfuerzos del gobierno de Chile no rendían frutos; los intereses chilenos de capturar la identidad de los peruanos, no funcionaba. La resistencia era más fuerte en los pobladores de Tacna y Arica. La importancia de Phillips en esta reunión, es fundamental; debido a que estuvo a cargo de la Guarnición de Tacna y Arica posterior a las batallas del 26 de mayo de 1880 y el 7 de junio de 1880 respectivamente, hasta agosto de 1881 . Phillips era consiente que la dominación de Tacna y Arica, no podía darse únicamente desde lo militar. Luego del Tratado de Ancón (20 de octubre de 1883), tenía claro que el plebiscito de Tacna y Arica; era un hecho circunstancial que no iba a poder ser dejado al azar de la voluntad de los tacneños y ariqueños peruanos la "Chilenización pacífica” (MONTENEGRO, 1919, págs. 17-18), no rendía frutos para los intereses chilenos de conquista; y promovía cada vez más resistencia en los pobladores de Tacna y Arica.

\subsection{Adoctrinamiento y patriotismo: El escultismo mal aplicado}

El 21 de mayo de 1909, se desarrolla la primera actividad fundacional del Movimiento Scout en Chile ${ }^{7}$. Cabe indicar que la fecha era la conmemoración del vigésimo aniversario del Combate Naval de Iquique; al acto inaugural el Dr. Cornelio Guzmán ${ }^{8}$, brindó las palabras inaugurales. El primer grupo scout se llamó Brigada Central, que luego pasó a llamarse "Grupo Alcibíades Vicencio del Instituto Nacional", honrando así la figura de su fundador después de su muerte. El 21 de mayo de 1909, se realiza la primera excursión al Puente Los Morros, en Buin. Al retornar de dicha excursión, los Scouts junto a Alcibíades Vicencio Th., visitan a la Viuda del Héroe de Iquique, Doña Carmela Carvajal de Prat. Esta fecha es destacada por el mismísimo Dr. Alcibíades Vicencio como la fecha de fundación oficial de la naciente Asociación de Boy Scouts de Chile.

El 15 de septiembre de 1910 Demetrio Salas junto con un grupo de scout marchó desde La Serena hasta Santiago, donde los esperaron diez mil scouts, en el Arco del Triunfo que se levantó en Honor a las "Glorias Militares" de la campaña del 79' en el parque Causiño, a lo cual el diario "El Mercurio" del 15-16 de setiembre de 1910, indica:

"Su porte marcial y disciplina fue elogiada por el Gobierno (Gobierno de Balmaceda)"; el Gobierno brindó todas las facilidades para desarrollar disertaciones a bordo del buque "Huáscar" (El Mercurio, 1910). Al respecto, el ministro de Guerra don Dario Zañartu; indicó en la Revista Militar, lo siguiente:

“(...) El esfuerzo de preparar a la juventud en el vigor, la robustez y el desarrollo del cuerpo es algo que requería para "Formar buenos militares, de modo que la institución de los Boy Scout es una excelente escuela preparatoria para el servicio militar/ despertando en los jóvenes "El espíritu Militar" Esto permitiría robustecer a nuestros hombres/ en términos físicos y morales; veo con desagrado como los jóvenes no consideran el servicio militar, por ignorancia de los deberes del ciudadano, del sacrificio del individuo en obsequio del interés común. Estos deberes son la "base constitutiva de la educación cívica".

\footnotetext{
${ }^{7}$ El primer Directorio General ya se había conformado el día 5 de mayo de 1909.

${ }^{8}$ Sobreviviente de "La Esmeralda"- sobreviviente del Combate Naval de Iquique 21.05.1879.
} 
(Zañartu , 1913). Por su parte Carlos Balmaceda - Ministro de Instrucción Pública, indico: [Sic] “(...) a través de sus actividades (Referencia al Movimiento Scout en Chile) los muchachos aprendian a conocer el país, sus sitios históricos, sus costumbres, el carácter nacional y desarrollan instintivamente el sentido patriótico”. (Diario El Mercurio, 1910, pág. 23). En el año 1913, con la llegada del presidente Theodore Roosevelt visitó Chile, con la consigna de brindar solución al Problema de Tacna y Arica (Sierra, 2013) ${ }^{9}$, fue invitado por el presidente Montt al buque "O'Higguins" a lo que el presidente Roosevelt, índico: [Sic] "Necesito hacer una peregrinación para visitar el monitor Huáscar, el más famoso y recordado blindado que haya existido y en el cual se ejecutaron los actos de heroísmo mayores que jamás se han hecho en otro blindado de cualquier nación del mundo". (Roosevelt , 1913). Esta declaración de Roosevelt, en franca alusión al heroísmo de Don Miguel Grau Seminario y reconocimiento al sacrificio del Perú, la declaración y la cuestión pendiente de Tacna y Arica no fue de mucho agrado para la comitiva chilena. Una vez terminadas las ceremonias Roosevelt, fue recibido por una comitiva de Scouts en el Parque Causiño (Revista "Dichos y Hechos, 1913, pág. 06). En esta actividad, los scouts - a cargo de sus instructores militares - desarrollaron evoluciones de combate al canto del Himno de Yungay ${ }^{10}$. Para el año 1914, la Asociación Scout de Chile contaba con cuarenta brigadas desde Arica hasta Punta Arenas como indica en su libro (ROJAS FLORES, 2006, págs. 22-26). La maquinaria del discurso nacionalista chileno, se vio abonado por la participación de Agustin Edwuars Mac Clure (Fundador del Diario El Mercurio) y Carlos Silva Vildósola entre 1911-1925, cuya padre, se habían visto favorecidos con el desarrollo de la Guerra del Pacifico; y cuyo resultado - promovido por la visión de Diego Portales- era mantener las zonas de expansión chilenas adquiridas durante la campaña del 79'a fin de mantener los beneficios económicos generados por la expropiación de las salitreras de Tarapacá y yacimientos minerales del sur del Perú y los antiguos territorios bolivianos expropiados por la fuerza a los capitalistas peruanos - entre ellos los del Héroe peruano Don Alfonso Ugarte Vernal. A fines de 1913, la formación de las brigadas scout en Chile, distorsionaban el enfoque humanista de Baden Powell; en el año 1912, Ismael Parraguez, creó "el Cancionero de la brigada" con la cual se adiestraba tropas a cantar las marchas militares de Yungay y marchas militares en honor a la campaña del 79’ y la Marsellesa. El año 1913 Samuel A. Lillo crea el Himno de los Boy Scout de Chile. Es decir, la maquinaria estatal tomó del escultismo la mejor herramienta de adoctrinamiento militar y movilización ciudadana de jóvenes en Chile. Al respecto Samuel A. Lillo, mediante "El Mercurio" con el asesoramiento de Phillips, generó el discurso fundamental de promoción de la identidad por medio del discurso del valor patrio y la necesidad del ciudadano chileno de preservar lo ganado con sangre. En franca alusión a la Campaña del 79'. Publicando en "El Mercurio", en la cual indica la nota del autor que precede a la proclama de Lillo, lo siguiente: [Sic] "Es profundamente satisfactorio para nuestro patriotismo, la formación de verdaderos hombres (Referencia a las brigadas Scout) para el desarrollo cívico de la juventud, para elevar el nivel moral de nuestro país”. (El Scout. Siempre listo, 1914, pág. 08). Samuel A. Lillo junto con Enrique Phillips, tuvieron a cargo la administración político-militar de Tacna y Arica entre 1880-1883, periodo en el cual se desarrollaron las primeras acciones de reducción de la identidad patriótica peruana, dentro de lo que llamaron los chilenos: "la solución pacífica". Estrategia mediante la cual, Chile, promovía la incorporación de pobladores chilenos en territorio ocupado y la expulsión de peruanos residentes de Tarapacá, Iquique, Arica y Tacna, a fin de mellar la identidad de los ex combatientes y patriotas en las áreas ocupadas. En este contexto, el desarrollo del escultismo en Chile como eje de adoctrinamiento militar durante 1909 a 1913; llevó a Baden Powell a manifestar en el año 1913 durante su visita a Chile en el Parque Causiño, lo siguiente [Sic]: "Nuestro adiestramiento no es militar; aun los ejercicios en conjunto que hacen gala las sociedades infantiles, se encuentran reducidos en el escultismo a un límite más estrecho, porque esos ejercicios tienden a destruir la personalidad, y uno de nuestros fines primordiales es desarrollar carácter individual a cada niño.” (ROJAS FLORES, 2006, pág. 105). Sin embargo, la política de adoctrinamiento prusiana, había sido instaurada como un ente de adoctrinamiento, llevado como política del estado desde el Ministerio de Instrucción Pública, Don Carlos Balmaceda. Por lo que el desarrollo de esa vertiente del "Escultismo" fue obligatoria en las instituciones educativas; sobre todo en aquellas zonas donde debía cimentarse el sentido de "Chilenidad", es decir los territorios ocupados en la Guerra del Pacifico. Sobre la política militarista- clerical promovida por el Chile, el 7 de Junio de 1914 en Arica (Revista Católica, 1914 ), el vicario castrense Rafael Edwuars, hizo una alocución sobre las "Glorias Militares" en la gesta de la "Toma y Asalto del Morro de Arica" donde se

\footnotetext{
${ }^{9}$ El "Washington Post" y el "New Yotk Herald" ponen de conocimiento la simpatía de Roosevelt a la causa peruana y ve con preocupación la situación de Tacna y Arica. La "Doctrina Monroe", fue un eje de solución, que no fue aprovechada por los gobiernos de la post guerra, en esencial por Leguía (presidente del Perú), que se encontraba conflictuado por un nuevo frente de combate- El conflicto con Colombia.

${ }^{10}$ Himno de alocución bélica, creado en 1838 por José Zapiola Cortes, donde conmemora la victoria de Chile en la guerra contra la Confederación Peruano Bolivianas que se oponían al General Salaverry (Perú).
} 
consagraba el valor de la "Juventud Chilena" en la promoción de los valores patrios consagrando la sangre chilena vertida en Tacna y en Arica, por lo que llamaba a los jóvenes a scout de Tacna y Arica a mantener "la chilenidad" ganada con sangre (El Scout. Siempre listo, 1914, págs. 3 - 4). La presencia Scout Chilena, estuvo destinada a ingresar e implementar la identidad chilena en los territorios ocupados durante la guerra del 79` y el amedrentamiento a los niños y adolescentes peruanos que aún permanecían en los territorios en disputa. Desde 1912, se inicia la campaña de la "Chilenización Violenta", época en la cual, la persecución, desaparición y hostigamiento a las comunidades peruanas se hizo latente por parte de la administración política - militar chilena, principalmente en los territorios de Tacna y Arica. Como indica (ROJAS FLORES, 2006), en su obra, la presencia de brigadas en las salitreras de Tarapacá e Iquique. No obstante, las denominadas "Ligas Patrióticas" o cuadrillas civiles de hostigamiento a la población peruana, usaba a las brigadas Scout de Arica y Tacna para el amedrentamiento y la violencia contra ciudadanos peruanos en las provincias cautivas. La actividad violentista y beligerante contra los ciudadanos peruanos se dio durante la gestión de Carlos Weguelin - empresario y espía chileno en Arica, durante la batalla de Arica- como refiere (VARAS OLEA, 1921). La persecución a las escuelas peruanas, el destierro de párrocos y maestras peruanos de Tacna y Arica, fue una política gubernamental establecida desde Santiago hacia las autoridades civiles chilenas en las provincias cautivas. El terror, se había convertido una política de estado para los peruanos.

\subsection{La encrucijada peruana en Tacna y Arica}

\subsubsection{La situación político - social de la población peruana en Tacna y Arica}

Después de la caída de Tacna y Arica, se generó la ocupación de los territorios peruanos y se dio inicio a medio siglo de cautiverio bajo administración chilena; posterior al Conferencia de Washington y la intervención de la Comisión Pershing y Lassiter, que demostró - en palabras de la prensa norte americana: “El reino del terror" generado por Chile, en el periodo más álgido de "la chilenización violenta" (19091929) ${ }^{11}$, por medio de estos informes cablegráficos, se daba a conocer el complejo escenario social que vivían los peruanos durante dicho periodo. La cuestión de Tacna y Arica, eran complejas desde 1884, en donde el Gobierno en el Exilio de García Calderón, planteaba y gestionaba la intervención Norte Americana, como mediador al problema de Tacna y Arica. Tarapacá había sido perdido en el Tratado de Ancón; sin embargo, - y en otro frente- la diplomacia boliviana y la chilena negociaban la salida de Bolivia de su mediterraneidad por medio de la anexión de Tacna y Arica a su territorio. El escenario era complejo y apremiante. El Perú, quedó en la debacle económica, política y moral posterior a la guerra. El mariscal Andrés A. Cáceres Dorregaray afrontada una crisis política y la acechanza del "avivato" político de los "Pierolistas", quienes combatían a Cáceres y las medidas de resistencia en las provincias cautivas ${ }^{12}$.

Al respecto las cartas de Modesto Molina a Nicolás de Piérola proponen complotar abiertamente con las facciones "Caceristas" en Tacna y en Arica. Estas guerras intestinas hacían vislumbrar una solución propia por parte de los mismos peruanos. En las cartas, se evidencia un afán "Colaboracionista" con las autoridades chilenas para delatar a los patriotas en resistencia de facción "Cacerista".

La división política y social era evidente, dos facciones políticamente antagonistas jugaban en contra de los peruanos en Tacna y Arica.

\subsubsection{La educación en Tacna y Arica bajo administración chilena}

Durante la "Chilenización Pacífica" (1880-1908), se construyeron en Tacna y Arica 40 colegios - los cuales (como antes mencionamos) impartieron de forma obligatoria la participación en el Movimiento Scout Chileno entre 1914-1929. Bajo pena de cárcel a aquel padre de familia que se negara a la educación chilena. En este periodo, los mayores de dieciocho años estaban obligados a servir en el ejército de ocupación (VARAS OLEA, 1921, págs. 289-294). Durante la primera etapa denominada "Chilenización Pacífica", se establecen políticas económicas, sociales y culturales que pretenden ganar la adhesión a la causa chilena por parte de los peruanos en Tacna y Arica por medio de acciones de colaboración y mejoramiento de su

\footnotetext{
${ }^{11}$ Washington Post / New York Herald

${ }^{12}$ Carta de Modesto Molina a Nicolás de Piérola. Tacna, 21 de mayo de 1895.
} 
calidad de vida, a lo cual (Telles, 1925), establece que Chile, mediante el uso de actividades persuasivas trató de ganar la aceptación de los peruanos en Tacna y en Arica; a lo que refiere: "Primero se trató de atraerlos (a los tacneños) con halagos, fiestas y promesas, que su patriotismo supo declinar cortésmente. Después, viendo que los hombres eran inaccesibles, se pretendió, por medio de la educación, ejercer influjo sobre los niños; pero los niños también supieron resistir." Sin embargo Chile, al haber desarrollado acciones de incremento de la infraestructura pública, productiva y de servicios en Tacna y en Arica, con lo cual podía generar adeptos entre la comunidad peruana, se vio obligado a tomar medidas más drásticas, pues los peruanos en Tacna y en Arica, no se "chilenizaban", muy por el contrario, abordaron los mismos elementos que le brindaron los chilenos para profundizar el sentimiento patrio hacia el Perú, por lo cual en el año 1900, se inicia el proceso de persecución de la identidad peruana, por medio del cierre de las escuelas en Tacna y en Arica; a lo cual refiere (Nieto del Rio, 1927), lo siguiente: "Es necesario discutir los argumentos sobre la cuestión basta para los propósitos del árbitro (Estados Unidos de Norteamérica) tomar las palabras expresas tomadas en el tratado de Ancón, según el Inciso $N^{\circ} 01$, del artículo $3^{\circ}$, en el cual se indica que el territorio debía continuar poseído por Chile, sujeto a las leyes de la autoridad chilena (Tratado de Ancón-Administración plebiscitaria - temporal de Tacna y Arica) \{...\}; por tanto, la voluntad de la población de Tacna y Arica deberá quedar expresa por "Voluntad Popular" unilateral, sin capacidad de reclamo por parte del Perú”. (Revista Chilena, 1927, pág. 88). Con lo cual, se establecía la política plenipotenciaria a nivel social, económico, cultural y educativo que Chile impondría en los territorios invadidos.

Al respecto (GONZALEZ, 2002); indica que: “\{...\} Un efectivo aparato ideológico en la chilenización de Tarapacá fue la escuela fiscal. La escuela pública se instaló en la pampa y en los valles de la pre cordillera, ambos espacios con mucha presencia de población tarapaqueña de origen peruano y boliviano. En este contexto, Sergio González sostiene que la escuela primaria fue un instrumento privilegiado para chilenizar $\{$...\}'. (GONZALEZ, 2002, pág. 253). Como se evidencia la participación del aparataje del estado chileno para promover la "desperuanización" de las cautivas, se desarrollaba a nivel multidimensional. Por otro lado, la publicación de (Cruchaga Torconal, 1927) "Revista Chilena" de 1927, hace relación a la Conferencia de Washington (1889-1890), en la cual el gobierno chileno entiende la injerencia política de Estados Unidos en la cuestión de Tacna y Arica; al respecto la conferencia de Washington y sus conferencias predecesoras, estipulaban marcos generales y tibios sobre la cuestión de las poblaciones peruanas de Tacna y Arica, sobre las acciones de ocupación por parte de Chile. La afectación a la vida e integridad de la población civil peruana de los territorios ocupados. De esta manera, la escuela fiscal marcó un cambio cultural en la región, desde la llegada de los "alfabetizadores", quienes se encargaron de educar a la "población chilena" (naturales peruanos y chilenos reasentados). A fin de poder votar en el plebiscito por Arica y Tacna. La política sistemática de chilenización, llegó hasta la formación de los maestros "chilenizadores". Asimismo, el imperativo de controlar las escuelas peruanas, era vital para los fines de "Extirpación" de la identidad peruana a través del control de la educación. Las autoridades chilenas mediante la persecución a los profesores peruanos, acusaron a estos últimos de "falsificar" la historia y promover el odio a Chile. Por otro lado, el discurso oficialista - nacionalista chileno presentaba la base de la ciudadanía y la participación política. Los dirigentes propagandistas establecían que los habitantes de Tacna y Arica debían elegir su nacionalidad considerando la posibilidad de un potencial progreso material; El plebiscito debía ganarse para chile, bajo la premisa del desarrollo, consolidando la adhesión de Tacna y Arica para Chile, refiere lo siguiente: "Así, con la raza chilena formada por la mezcla de la bravía raza autóctona y los aventureros vascos y castellanos, se ha formado en el aislamiento de sus montañas un pueblo sufrido y orgulloso, de constitución homogénea, de grandes condiciones asimilativas y notablemente emprendedor". (MONTENEGRO, 1919, pág. 10). Al respecto de la resistencia (TRELLEZ, 1925), refiere sobre la instrucción clandestina de los niños peruanos para mantener la peruanidad. "Primero se trató de atraerlos (a los tacneños) con halagos, fiestas y promesas, que su patriotismo supo declinar cortésmente. Después, viendo que los hombres eran inaccesibles, se pretendió, por medio de la educación, ejercer influjo sobre los niños; pero los niños también supieron resistir." (TRELLEZ, 1925, pág. 90). Asimismo, José María Barreto (Barreto, 1919), relata la postura de los nacionales peruanos en Tacna y Arica, sobre la endeble situación que dejo el Tratado de Ancón, a lo cual refiere: “(...) un sentimiento de intensa amargura se apoderó de todos los espíritus; pero los hijos de ambas provincias, acallando sus quejas y protestas, resolvieron acatar con patriótica resignación el convenio internacional que los alejaba por una decena de años de la comunidad peruana. Los tacneños y ariqueños que residían en esa época en Lima, menos resignados que sus hermanos rehenes, suscribieron inmediatamente un acta de protesta, que hicieron publicar y circular profusamente "a fin de que su contenido-decía el mismo documento-llegue a saberse en todos los lugares de la República y en todas las naciones". Hasta antes de 1900, indica (PALACIOS, 1974), que el desarrollo de la actividad pacifica de la "chilenización", propia de la motivación 
de ganar "La buena voluntad peruana" para adherirse al sistema social chileno en las provincias cautivas; a lo cual refiere: "Los clubes y las sociedades netamente peruanos, servían de continuo como sedes de reunión y distracción a ambos grupos. E inclusive se dio el caso de que muchos chilenos contrajeron matrimonio con mujeres del lugar y pasaron a radicarse en suelo peruano o viceversa. Se advertía, pues, una abierta y sincera armonía entre los dos sectores poblacionales. Igual cosa sucedía en las fiestas y celebraciones de nuestros connacionales”. (PALACIOS, 1974, pág. 85). La estrategia de la chilenización pacifica era - quizás- la acción propia de la convivencia de grupos humanos superpuestos por la acción discrecional de la violencia o de la pacificación; sin embargo, el hecho de la generación de una "nueva estructura social", no era más, que el camino menos sangriento para el dominio. Este proceso (“Chilenización Pacífica”), encontró resistencia desde el núcleo identitarios y fundacional que era el hogar y la escuela desde 1880 a 1929. La estrategia chilena de generación de obra pública y convivio hacia "el desarrollo de Tacna", no fue suficiente para ganar adeptos a su causa en Tacna y en Arica. Cabe mencionar que esta situación no es "ley en piedra", también hubo quienes, que por intereses políticos y económicos aceptaron la opresión como un medio para alcanzar sus fines (COX MÉNDEZ, 1944, pág. 197).

Como se mencionó anteriormente, el aparataje militar y administrativo de Chile durante la ocupación de las provincias cautivas y de las provincias anexadas de forma definitiva a Chile (Tarapacá), tenía que ser resuelto y rápidamente atendida, a fin de cimentar el proceso de "identificación" o superposición históricocultural. Por lo cual el gobierno chileno usó todos medios lícitos e ilícitos disponibles para lograr su objetivo. Al respecto, el 8 de marzo de 1910, Se publicó la normativa para el servicio militar (conscripto forzoso) de peruanos (tacneños y Ariqueños) en el ejército de Chile. La norma, fue publicada en el diario El Pacífico, indicando lo siguiente: "Servicio Militar de los Tacneños". Está extendido el decreto que llama al servicio militar obligatorio a todos los jóvenes nacidos en Tacna durante la ocupación chilena, los cuales serán enviados a los cuerpos de guarnición en Llanquihue y Magallanes". "El Gral. Vicente Palacios, actual inspector general del ejército, declara que respecto de la I división de ejército, pondrá gran empeño en mejorar el estado pecuniario actual, el alojamiento y la mantención de las tropas de guarnición en el norte, donde la vida es cada día más cara. Llenará los cuadros de línea y de contingente de las unidades, y que hará cumplir la ley del Servicio Militar Obligatorio en Tacna. Considerando la momentánea calma el Consejo Militar estudió las medidas que exigía la situación. Se sabe que figura en primera línea el envío de tropas al norte. Iquique será fortificado y se depositará allí una cantidad de carbón, suficiente para movilizar toda la escuadra en un momento dado. Todas estas medidas eran producto del estado de tensión que se vivía por esos días. El viernes en la noche el centinela que vigila el edificio que ocupan las oficinas de la jefatura del I ${ }^{a}$ División de Ejército, descubrió dos espías que andaban por los techos, con el propósito de entrar seguramente a robar documentos reservados. Al sentir el ruido el centinela subió al techo y disparó su revólver. Los espías huyeron. Es seguro que son peruanos. Se ha dado la orden de redoblar la vigilancia. La opinión pública se encuentra indignada con este motivo. Se confirma la resolución del gobierno de fortificar rápidamente el puerto de Arica, se artillará el Morro con cañones Krupp y se reforzará la guarnición de Tacna, con dos cuerpos de infantería, uno de caballería, uno de artillería de campaña y otro de ingenieros". (Diario El Pacífico, 1910). Al respecto (Arancibia Floody, 2014-2016), en su artículo: La Presencia del Ejército de Chile durante la ocupación de Tacna y Arica (1880-1929) publicado en el Anuario Academia de Historia Militar de Chile $\mathrm{N}^{\circ} 28$ : indica establecido en el relato de (BASADRE GROHMANN, 1959), en el cual detalla: "La guarnición militar de Tacna que antes de 1911 se componía del regimiento "Rancagua" y los zapadores "Atacama”, después de ese año creció con el regimiento de infantería "O'Higgins", los "Lanceros del General Cruz" y el regimiento de artillería 'Arica", admirables en su prestancia y en su disciplina. Gran interés reveló también las autoridades chilenas por desarrollar los establecimientos de instrucción pública. Eran ellos, en 1911, un liceo para niñas y otro para niños, una escuela profesional se había puesto en vigencia un eficiente sistema... para mujeres, dos escuelas superiores $y$ once públicas... Los directores de dichos establecimientos procuraban ganarse a la causa de su país a los alumnos más distinguidos y en algunos casos les ofrecían becas en Santiago. El himno nacional chileno se cantaba diariamente en los liceos $\{\ldots\}$...". (BASADRE GROHMANN, 1959, pág. 59).

Sobre lo anteriormente mencionado en cuanto al relato de Basadre y lo mencionado por el diario "El Pacifico", se evidencia un hecho constituyente de la acción coercitiva por parte de chile contra la población peruana, que quería mantener la peruanidad con insignia de resistencia en el periodo de la ocupación. Sobre la situación de los profesores peruanos y escuelas en Tacna, la crónica de Ricardo Oviedo Zavala, indica: "El 14 de mayo de 1900, el Intendente Palacios expedía el decreto que clausuraba las escuelas peruanas en el departamento. "Tacna, 14 de mayo de 1900-- Número 85 -- Vistos los antecedentes acumulados para comprobar el funcionamiento en Tacna de numerosas escuelas peruanas públicas y particulares, y teniendo presente la resolución gubernativa recaída en la materia, fundada en las consideraciones legales expuestas 
por el fiscal de la excelentísima corte suprema de justicia.... DECRETO.... No ha lugar a la autorización que solicitan algunos preceptores para abrir nuevos establecimientos de instrucción y quedan sin efecto las autorizaciones concedidas en época anterior. La prefectura de policía, en esta ciudad, y los subdelegados en las poblaciones rurales harán efectiva esta resolución, dando cuenta de las infracciones que fueran comprobadas. Anótese, publíquese y dése cuenta al supremo gobierno--- Palacios B.----Carlos $P$. Cotapos E.". Las vinculaciones políticas y económicas establecidas para justificar la posesión de Tacna y Arica, se basa en vínculos familiares directos; y la relación entre los ideólogos y políticos chilenos con ex combatientes de la campaña del 79'- los cuales también se reflejan en los interventores en la fundación del movimiento scout en Chile -; justificaron, el uso de una nueva estrategia de adoctrinamiento aparte de lo administrativo y militar. Sobre este tema cabe indicar el rol fundamental del Tnte. Crnel. Phillips, Eusebio Lillo, Edwards y otros. Sin duda alguna, los intereses de la clase política y económica chilena, tenía que suprimir cualquier foco de resistencia que afecte el objetivo nacional de Chile; es decir: aprovechar los yacimientos salitreros y minerales del sur peruano (Tacna y Arica). Al respecto, Alberto Muñoz Figueroa relata lo siguiente: "Al frente del regimiento Rancagua, por el lado en que se encuentra el casino de oficiales, se alza una casa de dos pisos de modesta apariencia, en la que funciona una escuela particular, cuyos alumnos, unos cuantos chicos de ambos sexos, son dirigidos y enseñados por una mujercita morena, de aspecto vulgar, que es la profesora y dueña del establecimiento. La susodicha señorita profesora nos profesa a los chilenos un franco y descarnado odio... Desde mucho antes del 28 de julio, me había fijado en los extraordinarios preparativos que hacía la señorita profesora para celebrar dignamente el aniversario Nacional del Perú. Todas las tardes reunía a sus alumnos y ensayaba con ellos la Canción Nacional del Perú, y los alineaba frente a nuestro casino para que viésemos nosotros a esos futuros soldados peruanos que, desde niños, sabían entonar su canción, a modo de desafio, frente a un regimiento chileno." (MUÑOZ FIGUEROA, 1914, pág. 25). En marzo de 1912, continúa como comandante de la primera División de Ejército en Tacna, el general de brigada Vicente del Solar, el que fue conocido como "el chilenizador", al respecto (Molinarie, 1912), relata sobre la acción integral de acoso y persecución a los peruanos de Tacna y Arica. Al respecto el relato indica: "Hoy la cosa ha cambiado tanto que el tacneño peruano es muy raro y casi desconocido. La chilenidad de esos territorios es ahora tan evidente que no necesita demostrarse”. (Molinarie, 1912, pág. 81).

La chilenización mantenía dobles estándares; los primeros mostrados de la diplomacia y el segundo desde la praxis de opresión y persecución a los peruanos, al respecto del problema de Tacna y Arica, Chile durante la "Conferencia de México" (1901-1902); en la cual se establece la disposición de "Arbitraje" a discreción y reconocimiento de los estados miembros. La chilenización violenta, abarcaba la persecución de clérigos, el cierre de escuelas, la prohibición y persecución de actos que promuevan la identidad peruana en los territorios cautivos y en los territorios en disputa posterior al tratado de Ancón (Tacna y Arica). En tal sentido; y ante la persecución, desaparición, secuestro, censura y el adoctrinamiento ideológico - militar (ROJAS FLORES J. , 2006), desarrollar un plebiscito, donde se garantice la voluntad y soberana elección de los naturales habitantes de la zona, en un ambiente de libertad y democracia, era un hecho poco probable por no decir imposible. Para (Palacios R., 1973) la "Chilenización", consistió en la aplicación de "todo género de medidas tendientes a hacer perder en ellos [ciudadanos] el carácter de peruanos, desvinculándolos en todo de su patria, el Perú, e infundiéndole el sello característico de la nacionalidad chilena". En tal sentido (Castillo Valderas, 2012), indica que "la Chilenización" se define como: "La presencia y hegemonía del Estado chileno se vio reflejada en la aplicación de una serie de políticas modernizadoras que buscaron transformar a las provincias de Tacna y Arica en una parte integral del territorio chileno. La historiografía peruana y chilena ha denominado como "chilenización" a la concreción de dichas transformaciones y a la aplicación de una política represora de cualquier sentimiento antichileno por parte de la población peruana. Esa política consistió en medidas violentas en contra de los habitantes peruanos y de sus instituciones en las provincias ocupadas, en la expulsión de ciudadanos peruanos de distintas clases sociales y en la importación de ciudadanos chilenos que podrían ser votantes en un eventual plebiscito. Así, fue posible observar por parte de la administración chilena políticas tendientes a facilitar el arraigo de familias nacionales en la zona y formar núcleos de población de habitantes chilenos, además de apoyar a los industriales y a la iniciativa privada $\{\ldots\}$ ”. (Castillo Valderas, 2012, pág. 65). La intervención de la clase política, eclesiástica, económica y militar en el desarrollo de la implementación del "Método Scout" para la formación extra-aulas de los jóvenes; y también como herramienta de formación, organización y control social - esto último queda de manifiesto tácito en las regiones cautivas (Tacna y Arica); un ejemplo claro es la participación del intendente don Antonio Subercaseaux, fue un allegado al Movimiento Scout en Chile; en el año 1911, en la propiedad familiar de los Subercaseaux- Juan Enrique Concha Subercaseaux, puso a disposición de los scout de Chile su propiedad para la formación de brigadas y el desarrollo de actividades. Por otro lado, el presidente Montt y el presidente Balmaceda reconocieron, brindaron importancia y 
masificaron el movimiento scout a nivel de todo el territorio chileno, lo cual incluía los territorios anexados y administrados posterior a la guerra del 79'. El apoyo gubernamental al movimiento scout quedó plasmado de forma legal con el Decreto Ley $N^{\circ} 520$ en septiembre de 1925, bajo el mandato del presidente Alessandri. Dándole el título de "Institución Nacional" (DEL BRUTO, 2016, pág. 08). Para facilitar el control de la educación de los jóvenes peruanos de las provincias se constituyó en la herramienta perfecta para inculcarles una sólida identificación con Chile. Ante este desafío, las autoridades chilenas no sólo clausuraron las escuelas privadas peruanas, sino que también se dieron a la tarea de acusar a los profesores peruanos de falsificar la historia y ser promotores del odio hacia Chile en los jóvenes de las provincias anexadas. En tal sentido los profesores peruanos siguieron dando clases en casas particulares, asimismo el Estado peruano enviaba dinero a las provincias para financiar las escuelas clandestinas (TRELLEZ, 1925, pág. 05) y para subsidiar a los sacerdotes peruanos que no habían sido expulsados aún por las autoridades chilenas en Tacna y Arica. Además, Chile utilizó su monopolio de la prensa, durante el periodo en conflicto, para ensalzar la identidad nacional, así como también las ventajas de vivir en un país próspero y progresista como Chile. Durante el año 1910 ocurrieron una serie de hechos que tensaron las relaciones chilenoperuanas y que afectaron la vida cotidiana de los militares chilenos en Tacna. Una de ellas fue la expulsión de los curas peruanos de Tacna y que fue relatado por la prensa de la siguiente forma: "Expulsión de los curas peruanos de Tacna, por Decreto del 3 de marzo de 1910, se expulsan los presbíteros José María Flores Mestras, Vitaliano Barros, José Félix Cáceres, Esteban Tocaffondi, Mariano Indacochea y Zeballos, Francisco Quiroz, Juan G. Guevara, para salir del territorio de la república, firmado por Máximo Lira Intendente y Eduardo Cisternas, secretario”. La opinión del general Holley, que permaneció una larga temporada en Tacna, sobre el asunto era "que la situación de la iglesia en la provincia, era inestable y desastrosa y que de ello era culpable el obispo de Arequipa, cuya terquedad a dado origen a la situación actual. Agregó que el clero peruano en Tacna, no inspira confianza a todos los fieles, porque los curas eran corrompidos y escandalosos. En este incidente el comandante de policía, en Tacna Manuel Ramón Barahona, fue el encargado de cumplir la orden de expulsión”. (Diario El Pacífico, 1910, pág. 05). Durante el periodo comprendido entre 1909-1912, la expansión del Movimiento scout en Chile fue una política de Estado, como señala (DEL BRUTO, 2016); según el autor mencionado establece que una de las obras importantes creadas por el Estado al servicio de los niños fueron los Boy Scouts. Fundada por Horacio Amaral con el apoyo de Horacio Molina, sargento de ejército en 1913 (Soto Correo \& et al, 2017), En la obra de (Vera Yannatiz, 1924) "Labor educacional chilena en Arica” En ella hizo un reporte del progreso realizado por el Estado chileno en materia de enseñanza pública. Escrito enmarcado dentro de una modernidad ilustrada que vio en la educación un camino eficiente hacia el progreso, por su retórica y grandilocuencia, tiene características de propaganda nacionalista. Tal finalidad parece plausible. El problema territorial chileno- peruano, parecía finalizar: un arbitraje estadounidense estudiaba los alegatos de las partes, quienes establecían sus títulos soberanos en la región.

\subsubsection{Las brigadas Scout en Tacna y Arica}

Los grupos scouts en Tacna y en Arica, eran dirigidos por ex combatientes de la campaña del 79’ o militares en actividad del ejército chileno, también muchos de ellos directores de los liceos en Tacna y Arica, eran miembros prominentes de "Las ligas patrióticas", como establecen (Dager Alva, 2005), indican que:

“Las ligas patrióticas”, se introdujeron en los territorios ocupados en la campaña del 79', con el único fin de hostigar, amedrentar y expulsar los bastiones de resistencia peruana, por medio de la violencia física y social”. (Dager Alva, 2005, págs. 201-205). Las brigadas scout alcanzaron un número importante de socios y una "correcta disciplina". Para Vera ${ }^{13}$ los primeros años de la institución los problemas económicos se resolvieron recaudando fondos con actividades populares. Eso permitió realizar ejercicios al aire libre donde se inculcó a los niños el amor patrio. Por ejemplo, la excursión realizada a Tacna, desde donde caminaron hacia el Alto de la Alianza, escenario de la Batalla de Tacna (1880). En otra expedición al mismo lugar, los niños recibieron una conferencia del "anciano y glorioso general retirado don Estanislao del Canto" (Rojas Flores, Moral y prácticas cívicas en los niños chilenos, 1880-1950., 2004). Las prácticas y los discursos de los scouts tenían un marcado acento militar. En 1914, aprovechando la conmemoración no. 36 de las batallas de Tacna y Arica, ganadas por Chile, los guías scouts organizaron el recorrido íntegro realizado por el ejército en 1880. En Tacna los niños presenciaron la teatralización in situ de la batalla. Vera, refiriéndose en tercera persona a su participación, indicó: “\{...\} El subdirector, que es a la vez

${ }^{13}$ Venerable Maestro de la Logia "Morro de Arica No29". 
profesor de historia, aprovechó los momentos de reposo en la marcha para ir dando explicaciones a los pequeños expedicionarios acerca de los sucesos que precedieron a la batalla del Campo de la Alianza, de este hecho de armas, y del alcance del general Lagos hasta la toma del Morro. \{...\}"”. (PALACIOS, 1974, págs. 194-202). La referencia enmarcada por (Soto Correo \& et al, 2017), es importante en la contextualización de la labor propagandista y adoctrinadora del escultismo chileno como parte de la maquinaria estatal para la "Chilenización" de las provincias cautivas. Cabe indicar la referencia hecha por el arzobispo castrense Edwards al conmemorar la batalla del 7 de junio; en la cual hace manifiesta su postura sobre la identidad y el servicio del joven chileno en la preservación y resguardo de la patria. En clara alusión a combatir los reductos de peruanidad en los territorios cautivos. Cabe indicar que en el periodo comprendido entre 1880 - 1900, Chile generó la creación de 40 establecimientos educativos en Tacna. El Tnte. Crnel Phillips, estuvo como parte de la junta de gobierno y administración en los territorios ocupados. Volviendo a Tacna y Arica, entre esos años en diferentes cargos y destacamentos. Luego de la fundación del movimiento scout de Chile (1909), como miembro encargado del Museo de Historia Militar (1895 1910); y posteriormente como parte de la comisión de formación de la aviación chilena (1913); en 1911, se encargó de la oficina de reclutamiento del Ministerio de Guerra, lo que refiere (Tupper Leon, 1979): " $\{\ldots\}$ El joven Enrique Phillips fue ascendido a teniente y su unidad embarcada rumbo al litoral nortino para cubrir las guarniciones de relevantes centros portuarios, urbanos y salitreros capturados al enemigo: Pisagua, Dolores, Iquique, Arica y Tacna. Cumpliendo guarniciones en Tacna y Arica pudo apreciar en directo Enrique Phillips la dura naturaleza que rodeó a los combatientes del Campo de la Alianza o Batalla de Tacna, el 26 de mayo, y a quienes se habían tomado el Morro a punta de bayoneta el pasado 7 de junio. Paisajes semidesérticos que se le grabarían y que volvería a contemplar años más tarde en significativa y honrosa comisión de servicio. \{...\}””. (Tupper Leon, 1979, págs. 78-80). En 1909, Phillips junto al fundador del movimiento scout en Chile Alcibíades Vicencio, reciben al célebre Lord Robert Baden-Powell en su primera visita oficial a Chile. En la cual el fundador del Movimiento Scout, realizó la exposición al presidente Pedro Montt, ministro de instrucción, al ministro de guerra y a varios funcionarios de alto rango en el gobierno de Montt, animado banquete en el cuartel del Pudeto y conferencia del general inglés en la Universidad de Chile. Phillips, luego de servir en el Batallón de Infantería Yungay como tercer jefe y en el Estado Mayor, fue comisionado en abril de 1900 para vigilar la construcción de una significativa cripta en el lugar mismo de la Batalla de Tacna o Campo de la Alianza, destinada a sepultar los restos mortales de los chilenos caídos allí en 1880 valerosamente. La Cripta de los Héroes fue mandada a erigir por el gobierno chileno en honor a los soldados "chilenos" caídos en la batalla de Tacna.

"La provincia en referencia permanecía todavía bajo administración de Chile. Al explorar el sitio en que ocurriera la batalla, encontró Phillips los restos momificados íntegros de un soldado chileno con su uniforme casi intacto, conservación natural extraordinaria en medio de un osario revuelto y polvoriento, reacio a entregar identidades. Ordenó encajonar el cuerpo de este héroe anónimo y lo mantuvo bajo cuidado personal en su casa durante largo tiempo”. (Tupper Leon, 1979, págs. 76-78). Al respecto, existe una discusión decimonónica sobre la fecha algunos historiadores hacen referencia por tradicional oral, más que documental, que la construcción se realizó entre el año 1909-1910, al investigar el relato documentado que se hace sobre Phillips y su tiempo de servicio a cargo del Museo de Historia Militar del Ejército de Chile, y a cargo del asesoramiento ministerial para la movilización y conscripción en el ejército chileno, lo cual es coincidente con la publicación de 1910 sobre "El servicio militar del Tacneño". Al respecto, la revista "Zig zag del 09 de abril de 1910, refiere: "\{...\} El gobierno de Chile en recuerdo de la sangre derramada por sus hijos en los campos de batalla durante la guerra contra el Perú en 1879, mandó erigir una sencilla cripta de acero \{...\} La cripta está coronada por una sencilla pirámide cuadrangular, toda blanca, con dos cañones entrelazados y una estrella. Más arriba se puede ver una corona de laurel que encierra esta inscripción: Pro Patria 28 de mayo de 1880 \{...\}’”. (Revista Zig Zag, 1910, págs. 09-10). Sin embargo, cabe mencionar que su exploración sobre los restos e iniciativa de sepultura se vislumbran en su acción de 1900. Por otro lado, la administración chilena a fin de adoctrinamiento y represión uso niños de las escuelas peruanas para este tipo de actividades. 


\section{Fotografía $\mathbf{N}^{\circ} 01$}

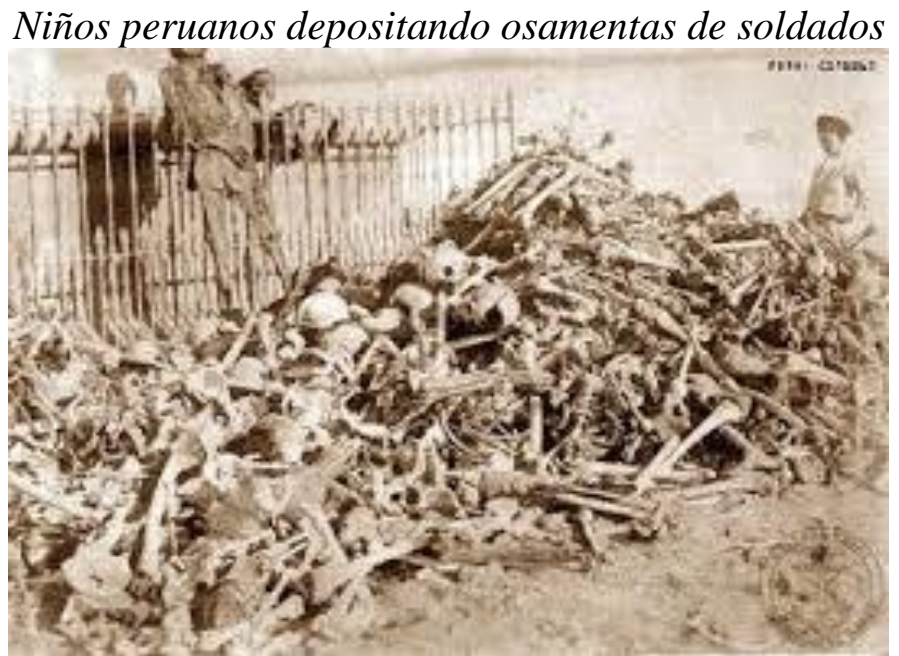

Fotografía: Revista Zig Zag. (1901). "Niños peruanos depositando osamentas de soldados". Lugar: Cerro Intiorko, Tacna, Perú. Autor de la obra: (Desconocido). Título: "Niños peruanos depositando osamentas de soldados". Imagen tomada de memoriachilena.cl [http://www.memoriachilena.gob.cl/602/w3-article8565.html]. Disponible: http://www.memoriachilena.gob.cl/602/w3-article-8565.html [Consulta: 2021, febrero, 26]

\section{Fotografía $\mathbf{N}^{\circ} 02$}

\section{Ceremonia de Homenaje soldados caídos de la batalla de Tacna}

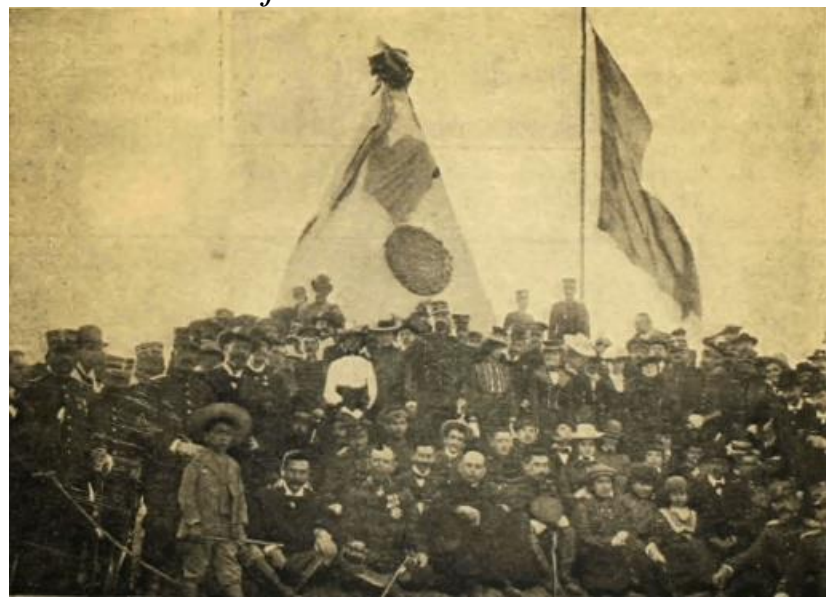

Fotografía: Revista Zig Zag.N²68 (1910). "Ceremonia de Homenaje soldados caídos de la batalla de

Tacna”. Lugar: Cerro Intiorko, Tacna, Perú. Autor de la obra: (Desconocido). Título: "Ceremonia de Homenaje soldados caídos de la batalla de Tacna”. Imagen tomada de memoriachilena.cl

[http://www.memoriachilena.gob.cl/602/w3-article-8565.html]. Disponible: http://www.memoriachilena.gob.cl/602/w3-article-8565.html [Consulta: 2021, febrero, 26]

Aunque no existe muchas referencias documentadas sobre "las brigadas juveniles" en Tacna, más la acción del grupo del Instituto Internacional de Comercio - Arica -1912-1914; existen relatos circunstanciales y orales; al respecto, se vislumbran algunos comentarios hechos por Salvador Allende y su infancia en Tacna. ${ }^{14}$ (Cruz-Coke M., 2003). Al respecto, de la infancia de Allende en Tacna se da entre 1900 -1910. Cabe indicar que en este periodo Allende, bajo la supervisión de Zoila Rosa Ovalle - natural de Lampa, Puno; Perú -, refiere sobre la infancia con "Chicho", lo siguiente: "En Tacna, "La mamá Rosa", nos reunía, encaramados en la arena, nos contaba las historias de los monumentos de Tacna" (Amoros, 2014, pág. 50)".

\footnotetext{
${ }^{14}$ Siendo su padre notario, la familia se trasladó a vivir sucesivamente en Tacna, Iquique, Santiago y Valparaíso, por lo que Salvador, en su juventud, llevó una vida itinerante estudiando en los respectivos liceos de esas ciudades. Así en 1919 estudió en el Instituto Nacional e hizo el servicio militar en 1925 en el Regimiento Lanceros de Tacna y también en el Coraceros de Viña.
} 
La segunda etapa de allende en Tacna, se da en la época consignada entre 1924-1928, a lo que refieren: "Chicho se recibió de bachiller y la familia retornó a Tacna". (Amoros, 2014, pág. 63). Su padre se integró al grupo de abogados encargado de la defensa de Chile en la tramitación plebiscitaria de Tacna y Arica. En esa tarea conoció de cerca a Agustín Edwards Mac Clure, propietario del diario El Mercurio y abuelo de quien 45 años después sería uno de los peores enemigos de su hijo menor. La madre, mientras, hizo amistad con la esposa del entonces capitán Carlos Ibáñez del Campo, matrimonio que habitaba una de las casas vecinas. Salvador ingresó como voluntario al servicio militar en el Regimiento Coraceros de Viña del Mar. Pidió su traslado al Regimiento Lanceros de Tacna, desde donde egresó como oficial de reserva del Ejército. (VARAS OLEA, 1921, pág. 75). Por su parte, Jorge Basadre, indica: “ \{...\} en 1900, el ex prefecto de Pisagua asentado en Tacna don Modesto Molina, emitió sendos documentos a don Nicolás de Piérola para la reorganización de la resistencia educativa de Tacna ante la chilenización. \{...\}”." (BASADRE GROHMANN, 1959, pág. 57). Basadre da relato a las vejaciones que sufrían los peruanos en estos años (1900-1925), indicando sobre el acontecimiento sufrido por Freyre ${ }^{15}$ donde un grupo de "Matones" agredieron a este por un hecho suscitado contra el juez chileno Balniot, indicando que "le haría comer su artículo - publicado en el diario "El Tacora". Este tipo de agresiones no eran infrecuentes para atemorizar a los peruanos; sin respetar edad, condición ni sexo. Sin embargo, don Alberto Vicherat (Vicherat, 1965), compañero de estudios de Salvador Allende en el Colegio de la Calle Alto de Lima, recordaba que una de las principales acciones que se desarrollaron en la época escolar; era visitar el campo de Batalla; entonar el Himno a Yungay; y dar vivas y vítores a Chile; aquel niño que se rehusase a hacer esto era golpeado brutalmente y "llevar a lomo" a los restos humanos dispersos en el campo del Alto de la Alianza; hacia una pequeña cripta ubicada en el Intiorko, el cual era el cerro de ingreso a la ciudad de Tacna. Asimismo; Vicherat comentaba que en los años 1912-1915, se hacían campamentos y adiestramiento a los alumnos con monitores militares (Revista Católica, 1914 , pág. 12). Las circunstancias temporales e históricas brindan aproximaciones valederas a lo acontecido en Tacna y Arica en estos años; cabe indicar que la chilenización; buscaba abarcar todos los aspectos de la sociedad peruana asentada en Tacna y Arica.; al respecto, la intervención de "Los Tacneños Chilenos", refieren una acción más allá de la dialéctica; sino muy por el contrario una acción discursiva y practica fáctica, es el caso de Centro Social Patriótico de Mujeres Chilenas de Tacna" a su presidente honorario, que era el general Valenzuela. (1890-1928). La cual promovió acciones de delación y chantaje a la resistencia peruana, - promovida principalmente por mujeres peruanas de Tacna y Arica. En 1913, Horacio Amaral, fundador de los scouts, con motivo de una supresión parlamentaria de presupuestos para el instituto fue entrevistado por El Mercurio, explicando que, ante aquella, el cierre del recinto era inminente. Tal presupuesto no bastaba para mantener el internado, dos preparatorias, un subdirector y un inspector general; vale decir, la educación chilenizadora decaería irremediablemente. En palabras de Amaral: "Las familias peruanas que viven en los pueblos del interior de la provincia de Tacna y aún en la de Tarapacá, mandan anualmente a sus hijos al Instituto de Arica. Suprimiéndose el internado habrán de mandarlos a Lima, pues no existen en ninguna de las tres provincias del norte otro establecimiento de instrucción que cuente con internado, con evidente perjuicio para la obra chilenizadora que el país tiene el derecho de esperar de la labor de este plantel (...)”. (PALACIOS, 1974). El profesor Amaral estaba consciente de la importancia de una educación estatal que forjara y puliera el amor hacia Chile. En la misma entrevista explicó que "la obra de arraigamiento de las familias chilenas en aquella región nunca podrá ser completa si no se les proporcionan los medios de educar a sus hijos manteniendo establecimientos de instrucción. Dentro de este, la institucionalización del cuerpo de Boy Scouts favoreció la cristalización de aquellas ideas que ligaban el militarismo a la modernidad y a la civilización. Así, parece plausible que un número importante de actividades de los escultistas guardara relación con una educación espartana de la cual, tempranamente, un destacado profesor señaló: "Es indispensable dar a la institución de los Boy Scouts en Chile un carácter más bien pedagógico que militar, puesto que el principal elemento lo componen los niños [...]". (Revista "Dichos y Hechos, 1913).

Los scouts experimentaron momentos de patriotismo. Por ejemplo, en 1914 el Gobierno coordinó el traslado de las cenizas de los muertos en La Batalla de Arica (1880) desde la Iglesia Parroquial hacia la Virgen del Carmen, en los faldeos de esa formación rocosa. Para la ocasión, el vicario general castrense pronunció palabras que reforzaron el pasado heroico de los pueblos chileno y peruano, siendo escuchado por la "tropa de Artillería de Costa, que guarnece el puerto, algunos miembros de la sociedad de veteranos del 79, los Boy Scouts del Instituto Comercial, las diversas escuelas públicas y todas las sociedades obreras". Frente a ellos se abrió paso una comisión que transportó cinco sarcófagos.

Otro de los ceremoniales significativos para los muchachos fue el "Juramento a la Bandera", donde se probaba su fidelidad con la patria. Los documentos señalan que desde 1917 realizaron tal actividad. Para

\footnotetext{
${ }^{15}$ Ref. Periodista tacneño, cofundador del diario "El Tacora"- periódico de presencia.
} 
otorgarle mayor eficacia simbólica, un grupo militar viajaba desde Tacna, capital provincial, hacia Arica, donde un teniente del Regimiento Rancagua coordinaba la ceremonia que alcanzaba su clímax con la oración patria: "¡Juro por Dios y por esta bandera servir fielmente a mi patria ya sea en mar o tierra o en cualquier lugar hasta rendir la vida si fuese necesario, cumplir con mis deberes y obligaciones militares conforme a las leyes y los reglamentos vigentes, obedecer con prontitud y puntualidad las órdenes superiores, poner todo empeño en ser un soldado valiente, honrado y amante de mi patria!" (Revista Católica, 1914 ). El mismo ceremonial se realizó dos años después, cuando los discursos iniciales estuvieron a cargo del masón Carlos Grebe y el teniente Hernán Vergara. Un diario local afirmó que el "acto del juramento a la bandera por los boy scouts fue emocionante". En otra ocasión, después de la misa de campaña los scouts fueron conducidos al frente de la casa del gobernador, donde en presencia de las autoridades y el pueblo se realizó la jura de la bandera. El mismo Grebe, presidente de los scouts, ofició de orador comentando la importancia moral del acto. El comandante de la brigada, profesor Miguel Ahumada, pronunció las siguientes palabras: "Scouts: Con el juramento que acabáis de otorgar, adquirís un compromiso solemne. De hoy en adelante estáis más que nunca obligados a ser respetuosos con vuestros superiores, modelos de hijos y hermanos en vuestro hogar y ejemplo de todas las virtudes cívicas que comprometen más a los miembros de esta Institución que a cualquier simple ciudadano. Siempre listos, es vuestro lema, siempre listos para toda labor benéfica y patriótica en pro de la humanidad; para obedecer en el acto cuantas órdenes emanen de vuestros jefes, para socorrer al pobre; para ayudaros unos a otros y para practicar el bien en cuanto esté al alcance de vuestras fuerzas. Desde este momento formáis parte de una cadena cuyos eslabones circundan el mundo entero; procurad hacerla cada vez más sólida en beneficio de la fraternidad universal y que jamás el odio anide en vuestros corazones". (Diario El Ferrocarril, 1920, pág. 06).

\section{Fotografía $\mathbf{N}^{\circ} 03$}

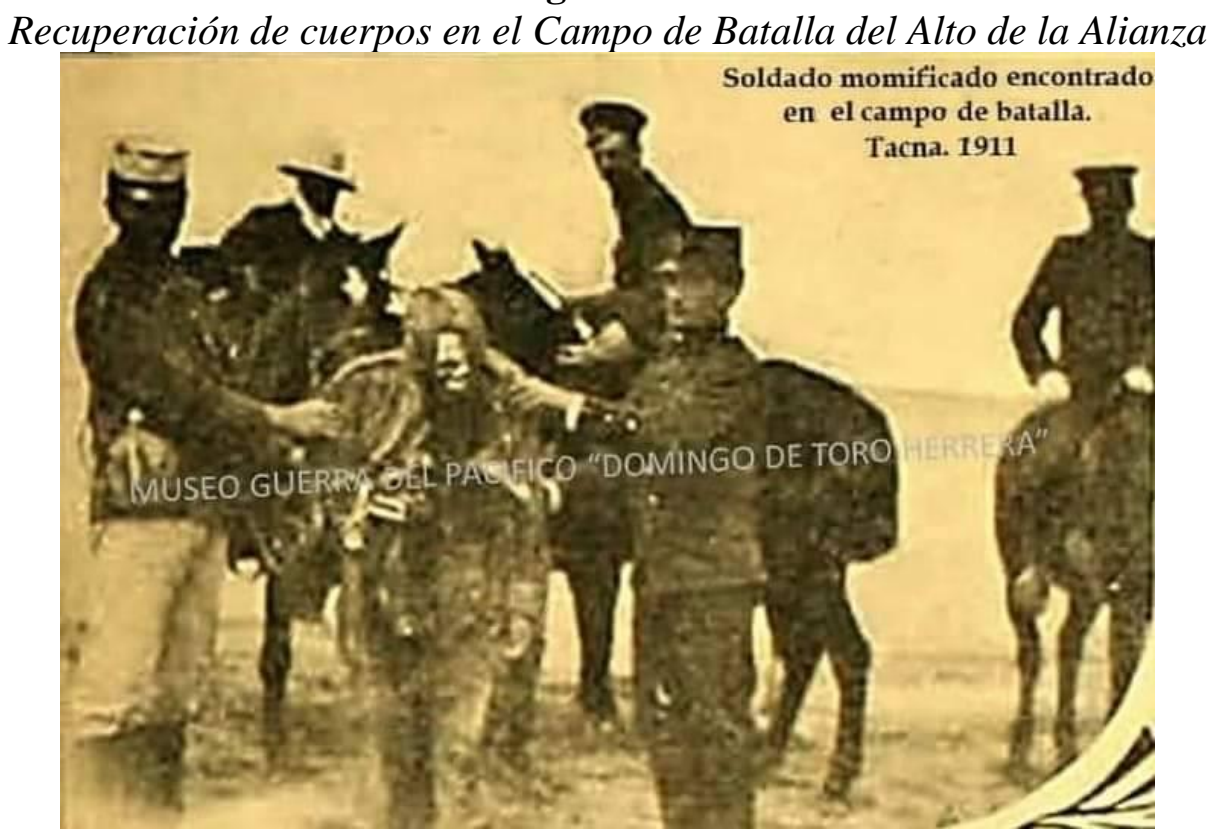

Fotografía: Museo de Guerra del Pacífico "Domingo Toro Herrera" (1911). "Soldado momificado de la batalla de Tacna". Lugar: Cerro Intiorko, Tacna, Perú. Autor de la obra: (Desconocido). Título: “Soldado

momificado de la batalla de Tacna". Imagen tomada de Asociación de Estudios Históricos de Tacna [https://www.facebook.com/Asociaciondeestudioshistoricos/photos/a.588194631877632/7233395383631 40/]. Disponible:

https://www.facebook.com/Asociaciondeestudioshistoricos/photos/a.588194631877632/72333953836314 0/ [Consulta: 2021, febrero, 26] 
En 1920, la agrupación estuvo comprometida con una de las primeras manifestaciones que solicitaba al gobierno chileno la anexión definitiva de Tacna y Arica. El Ferrocarril, dirigido por Vera publicó el llamado para asistir a la movilización nacionalista. Durante estos años la "Chilenización", se volvió violenta, dejó el discurso para tomar acciones concretas contra los peruanos en Tacna y en Arica; y "cortar cabeza" a cualquier foco de resistencia de peruanidad. Al respecto (del Brutto, 2016); refiere al llamado establecido por Ladislao Errázuriz Lazcano, “ordenó una movilización general de alto costo. Los regimientos se dirigieron al norte, en medio de inconmensurable efusión patriótica" (FERNANDEZ VALDEZ, 2004, pág. 351). La guerra, no estalló. Las tropas circularon por Tacna y Arica tras un enemigo imaginario. Los coordinadores de los Boy Scouts ofrecieron la ayuda militar de sus niños. En Arica, rápidamente se tomaron las medidas necesarias para cumplir la orden central y profundizar la instrucción militar de la brigada. La prensa escribió: “\{...\} La simpática institución de los Boy Scout que fundó en Santiago el general Baden Powell y que se ha difundido por todo el país, ha resuelto en vista de la situación internacional actual, que todas las brigadas reciban instrucción militar para estar preparados en un caso dado de servir de portadores de mensajes y de otros servicios similares en los regimientos. El presidente de la Institución en este puerto recibió la comunicación del Directorio General de Santiago en que le daban cuenta del acuerdo adoptado quien inmediatamente hizo las gestiones del caso para conseguir instructores militares $\{\ldots\}$ \}. (Diario El Ferrocarril, 1920, pág. 07). La dialéctica nacionalista y militarista en el sur del Perú (Tacna y Arica), se vio desnudada con la conmemoración de la Batalla de Arica también actualizó la memoria nacionalista. En ocasiones, como la del 7 de junio de 1923, las estrategias para activar el recuerdo heroico se diversificaron. Se sumó al tradicional desfile, canciones patrias y "embanderamiento" de la ciudad, el simulacro del combate entre las tropas chilenas y las peruanas (personificadas por chilenos). Chile, había empezado con la desperuanización de forma flagrante pese a que las misiones de Pershing y Lassiter buscaban el mecanismo jurídico y de "Buena voluntad" por parte del gobierno de Estados Unidos para solucionar los atropellos que venían siendo víctimas los peruanos en Tacna y Arica; Basadre y Figueroa, así como Vargas han escrito sobre el tema. Asimismo, (Yepes, 1999) relata las vejaciones que tenían los peruanos en este periodo. Sobre el empleo de los jóvenes de Tacna y Arica, en las remembranzas de las efemérides militares chilenas establecidas en el Calendario Escolar por el gobierno chileno, se indica: "\{...\} la uniformidad de pensamiento, sentimiento y acción de todos los que habitamos estas regiones en que con más vehemencia e intensidad se profesa y se hace florecer el culto a la Patria. Es por eso que el gesto de los profesores y estudiantes de Arica en estos precisos momentos en que se pretende disputar la soberanía de Tacna y Arica, son voces elocuentes que proclaman ante el mundo a una nueva generación chilena \{...\}’”. (Diario El Ferrocarril, 1920, pág. 07).

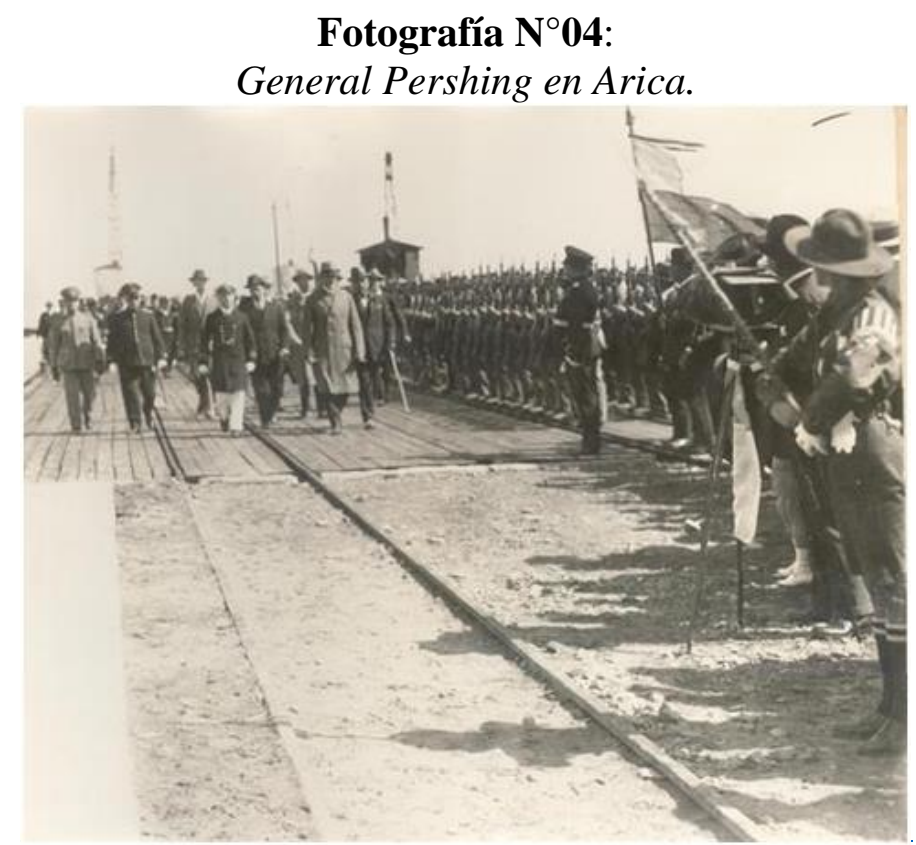

Fotografía: Revista Zig Zag. (1920). “General Pershing en Arica.”. Lugar: Arica, Chile (Ocupada). Autor de la obra: (Desconocido). Título: "General Pershing en Arica”. Imagen tomada de memoriachilena.cl [http://www.memoriachilena.gob.cl/602/w3-article-8565.html]. Disponible: http://www.memoriachilena.gob.cl/602/w3-article-8565.html [Consulta: 2021, febrero, 26] 


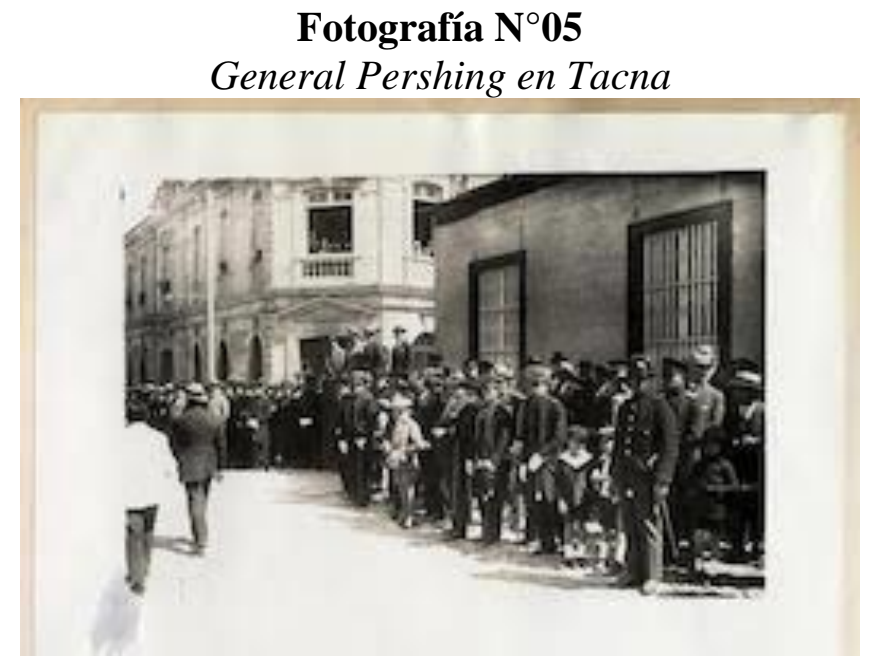

Fotografía: Revista Zig Zag. (1920). “General Pershing en Tacna.”. Lugar: Tacna, Chie (Ocupada). Autor de la obra: (Desconocido). Título: “General Pershing en Tacna”. Imagen tomada de memoriachilena.cl [http://www.memoriachilena.gob.cl/602/w3-article-8565.html]. Disponible: http://www.memoriachilena.gob.cl/602/w3-article-8565.html [Consulta: 2021, febrero, 26]

Como refiere (Soto Correo \& et al, 2017, pág. 93): "En las manifestaciones del 26 de julio y del 24 de agosto de 1925 los scouts tuvieron una participación distinguida. El objetivo de la primera, organizada por la gobernación departamental, era recibir a los miembros de la comisión plebiscitaria de Chile, encabezada por Agustín Edwards McClure (fundador de El Mercurio). El lugar de reunión fue el puerto. Por la mañana, escribió un periodista: “\{...\} llegaban al muelle el orfeón de Policía, la brigada de Scouts del Instituto Comercial y los alumnos de este establecimiento; delegaciones de las sociedades Unión de Socorros Mutuos, Unión de Empleados, Bomba O’Higgins, Veteranos del 79', Asociación de los Hijos de Tacna y Arica, de la Liga de Fútbol, y otras, y numeroso público, que, en los momentos de pisar tierra firme, tributó al señor Edwards y acompañantes entusiastas recibimientos. \{...\}”. (Diario El Ferrocarril, 1925, pág. 03). El hecho tuvo expectativa entre tacneños y ariqueños peruanos y chilenos. La presencia de Pershing vislumbraba "Una luz al final del túnel” para los peruanos; y para los chilenos, una forma propagandística para ahondar la creencia de la "\{...\} chilenización de las cautivas. A la segunda concentración acudió un gran número de chilenos de Tacna. Arica estaba embanderada a la espera del paso de los marchantes. Formaron parte de esta actividad "las sociedades y gremios chilenos del puerto y los boy scouts y alumnos de las escuelas \{...\}.” (Diario El Ferrocarril, 1925, pág. 03). Al respecto (Zagal, 2018, pág. 396), nos indica: “\{...\} Este sentimiento de triunfo fue representado en la revista Sucesos en distintas ocasiones por el caricaturista "Chao", pseudónimo del dibujante Raúl Figueroa Ruiz, quien será el autor de la mayor parte de las "caricaturas plebiscitarias" analizadas en el presente trabajo. La primera de estas imágenes, publicada el 12 de marzo de 1925, nos muestra al presidente Coolidge levantando el brazo, en señal de triunfo, de un boxeador que lleva escrito en su vientre la palabra “Chile. \{...\}”. (Ruz \& et al, 2015, pág. 802). El uso del aparataje propagandístico por parte de Chile, fue la "Quinta Columna" de la guerra silenciosa que se cernía en la cuestión de la identidad nacional de ariqueños y tacneños. La colosal manifestación, como la catalogó un periódico, esperaba realizar la más grande de todas las demostraciones de nacionalismo efectuadas hasta entonces. Cada institución participante portaba su estandarte. Finalmente, el desfile que reunió a más de treinta asociaciones fue encabezado por los Boy Scouts (Diario El Ferrocarril, 1925, pág. 02) . El accionar de las "Ligas patrióticas" y el adoctrinamiento de las "Brigadas Juveniles" y grupos scout; inician la agresión a los ciudadanos peruanos. Este periodo 1925-1926 no solo se distinguió por la alta movilización nacionalista, sino también por los innumerables episodios callejeros de violencia xenofóbica (Diario El Ferrocarril, 1926, pág. 02). (Soto Correo \& et al, 2017) ${ }^{16}$, refieren: Si bien este tipo de prácticas violentistas fue ejecutado por varones de edades más avanzadas y no específicamente niños, los scouts también estuvieron implicados -indirectamente- en algunos hechos. Así, por ejemplo, dio cuenta

${ }^{16}$ [Sic]: "A este cholo hay que matarlo como a un perro: violencia nacionalista y justicia en Arica durante los preparativos del plebiscito entre Chile y Perú (1925-1926)”, en Tiempos violentos. Fragmentos de Historia Social en Arica, ed. Alberto Díaz, Luis Galdames y Rodrigo Ruz (Arica: Universidad de Tarapacá, 2014): 85-100. En Perú, años antes se había publicado una dura crítica hacia la chilenización. 
el diario dirigido por Vera, en la noticia titulada "El eterno ridículo" (Diario El Ferrocarril, 1926, pág. 03) refiriéndose al miedo experimentado por los ciudadanos peruanos. Siguiendo el testimonio chileno, un grupo de cinco Boy Scouts embromaron a unos peruanos que habitaban la periferia ariqueña. Por este tiempo, la justicia de la región estaba ambiguamente ejercida por tribunales chilenos y estadounidenses, estos últimos recibían e investigaban las denuncias de los peruanos violentados. Un historiador chileno, al respecto, comentó: "Los peruanos $\{\ldots\}$ tomaron la costumbre de romper sus propias ventanas, a palos, y dar gritos de socorro para que se les salvase de chilenos imaginarios \{...."”. (El Ferrocarril, 1926, pág. 03). En ese contexto judicial, un ciudadano peruano de apellido García, "con una cara de vela de cebo \{...\} casi lloraba ante los norteamericanos diciendo que a él era a quien habían querido matar [unos scouts] y que los crímenes seguirían sino se ponía remedio inmediato a este mal". La policía dio con los escultistas, poniéndolos después a disposición del capitán Backus quien "les recomendó decir la verdad como buenos scouts". La retórica del diario era propia del amedrentamiento sistemático; y del adoctrinamiento recibido en pro de odio y rechazo a los residentes peruanos de Tacna y Arica. En este sentido artículo indica: " $\{\ldots\}$ Cuál no sería la sorpresa de nuestro distinguido militar al tener frente a él a cinco jóvenes entusiastas que hacían vida de campaña y trabajaban al igual que los norteamericanos enseñando a sus hijos. Oídas las declaraciones de los Scouts, examinadas las armas, comprobándose que eran dos rifles de salón, se procedió a sacar una fotografía para presentarla en cualquier caso de reclamación, mientras el resto de espectadores, entre ellos varios americanos soltaron la risa al ver al cholo todo amostazado, mientras alguien decía: Estos peruanos ya empiezan a cansar, son como las mujeres \{...\}” (EL DIOS CAUTIVO. LAS LIGAS PATRIÓTICAS EN LA CHILENIZACIÓN COMPULSIVA DE TARAPACÁ (1910-1922), 2005, pág. 95). Como refiere Basadre ("Infancia en Tacna", 1959, págs. 22-23), la violencia no fue un hecho aislado en Tacna; durante el periodo consignado entre 1915 al 1928, el empleo de las "Ligas Patrióticas", la utilización de mecanismos de terrorismo de estado por parte del Gobierno Chileno; el cual generaba acciones paramilitares de agresión y hostigamiento a la población de Tacna. En tal sentido, el trabajo realizado por (Dager Alva, pág. 98); manifiesta la forma violenta en la cual se desarrolló esta acción. En el caso de Tacna; la violencia se caracterizaba por los agentes pro-chilenos violentistas, a quienes se les definió como "Mazorqueros" o "Cowboys" (PALACIOS, 1974, págs. 156-158). En periodo consignado entre 1915-1928; los "mazorqueros" promovieron acciones de desperuanización del territorio de Tacna; la primera forma de amedrentamiento se dio por medio de los "Pinta Cruces"17.

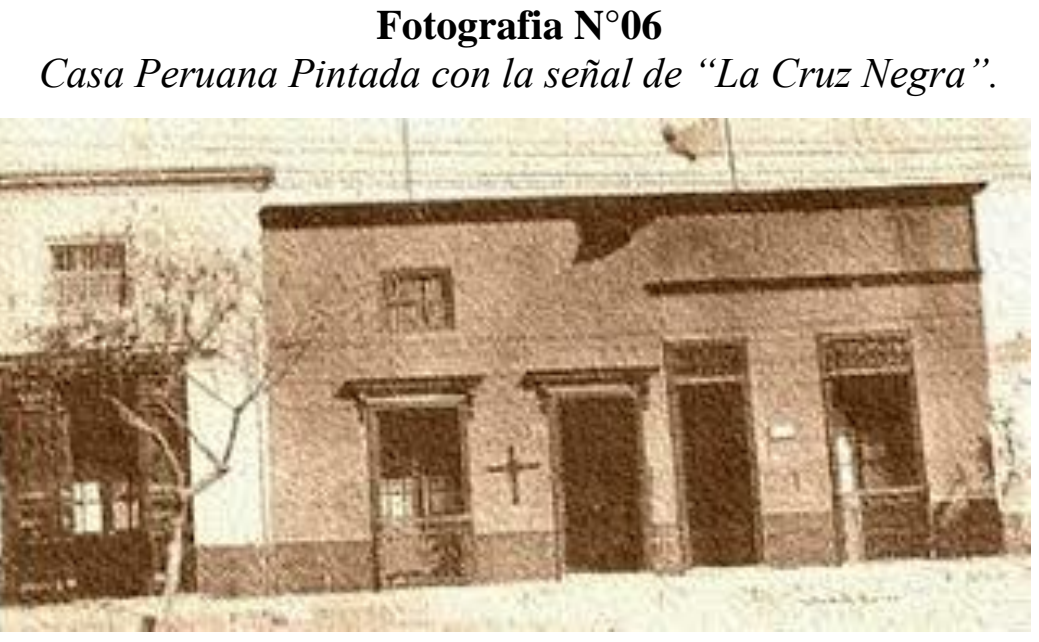

Fotografía: Colección: Tacna, bajo dominio de Chile - Archivo Regional de Tacna (1926). “Casa Peruana Pintada con la señal de "La Cruz Negra". Lugar: Tacna, Perú. Autor de la obra: (Desconocido).

Título: "Casa Peruana Pintada con la señal de "La Cruz Negra". Imagen tomada de Wikipedia

[https://es.wikipedia.org/wiki/Archivo:TACNA_1926_CRUZ_NEGRA.jpg]. Disponible: https://es.wikipedia.org/wiki/Archivo:TACNA_1926_CRUZ_NEGRA.jpg [Consulta: 2021, febrero, 26]

\footnotetext{
${ }^{17}$ Acción por la cual, los "mazorqueros" marcaban con una cruz negra las casas de patriotas y directores de escuelas clandestinas por fomentar la peruanidad. El símbolo (la cruz negra) significaba que la persona tenía 24 horas para salir de la ciudad, caso contrario podría desaparecer, las "Ligas patrióticas", eran la facción violenta y paramilitar del gobierno chileno.
} 
Al respecto, el "New York Herald" y el "New York Times" y "Washington Post” indicaban: “mientras Perú denunciaba la "conducta terrorista de Chile" en Tacna y Arica, los chilenos declaraban que esto era una campaña peruana -apoya por los norteamericanos- y acusaban a la delegación peruana de retardar los procedimientos para evitar el plebiscito. Hacia octubre de 1925, los diarios norteamericanos recibían reportes del general Pershing, quien estaba convencido del terrorismo chileno de estado; y consideraba, que este (la violencia contra los ciudadanos peruanos) estaba "cerca de acabar con su paciencia debido a la falta de avance" y que la "alternativa ante adicionales retrasos podría ser el abandono por parte de los norteamericanos de llevar a cabo la decisión del presidente Coolidge". (Llanos \& Nelson, 2011, págs. 4549).

\section{Fotografia $\mathbf{N}^{\circ} 07$}

Peruanos expulsados de Tacna. 1920-1928

\section{Peruanos expulsados de Tacna}

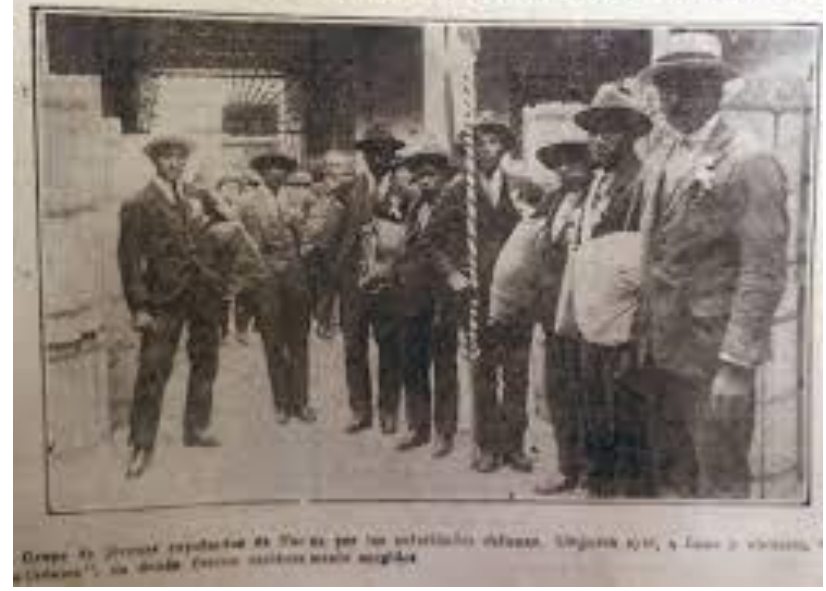

Fotografía: Colección: Tacna, bajo dominio de Chile - Archivo Regional de Tacna (1926). "peruanos expulsados de Tacna. 1920-1928. Lugar: Tacna, Perú. Autor de la obra: (Desconocido). Título: "Casa Peruana Pintada con la señal de "La Cruz Negra". Imagen tomada de Archivo Regional de Tacna.

Disponible: Archivo Regional de Tacna. [Consulta: 2020, enero, 26]

Para julio, se elaboró una programación cívica para recibir al canciller Conrado Ríos Gallardo, quien había pasado parte de su juventud en la ciudad, realizando allí el servicio militar y quien también había participado en 1920 en la "Guerra de don Ladislao" (FERNANDEZ VALDIVIA, 2004, pág. 521). Como en ocasiones pasadas, las agrupaciones chilenas lo aclamaron y desfilaron ante él. La comunidad se hizo presente con los colonos extranjeros, los portuarios, los funcionarios públicos y los niños del "Instituto Comercial, Brigada de Boy Scouts, Escuela modelo" (Diario El Ferrocarril, 1927, pág. 02), etcétera. Una presentación similar se realizó en honor del ministro de Guerra, Bartolomé Blanche, quien visitó Arica el 19 de octubre. La Comandancia de Armas dispuso que fuera recibido por el regimiento de artillería montada Velásquez no. 5 más un grupo de dos baterías de bandas de músicos. La prensa informó: "Concurrieron a la estación las brigadas de boy-scouts del Instituto Comercial y de la Escuelas, además de numeroso público" (Diario El Ferrocarril, 1927, pág. 05). La narrativa oral y escrita; no refiere una fecha de conformación "formal" del escultismo chileno en Tacna; y probablemente se resume en lo siguiente:

"No refutó la aseveración insistente que se hizo en el sentido de que Arica ya era irreversiblemente chilena mientras Tacna continuaba aún fiel al Perú; y para ello desconoció lo que sabíamos hasta los más ínfimos protagonistas en la campaña de 1925 y 1926, el hecho conmovedor de que la zona rural ariqueña seguía siendo, en buena parte, heroicamente peruana” (BASADRE GROHMANN, 1975, pág. 411). Para Chile, la resistencia de Tacna; era un factor de exacerbación para agredir de forma más violenta a los focos de resistencia, pese a ello, Tacna resistió y perduró en su identidad cultural y nacional (CASTRO OYANGUREN, 1919, pág. 87) ${ }^{18}$.

18 "Op Cit: P. 87: “\{...\} "El 23 de diciembre, a las 11 de la noche, después de una reunión de la "Liga Patriótica», efectuada en el Teatro Municipal, una poblada escoltada por la policía, recorrió la población, deteniéndose delante de las casas de algunos peruanos, para insultarlos y darles un plazo dentro del cual debían de abandonar la provincia. Al día siguiente, desde las 9 de la noche, una horda de más de doscientas personas, compuestas en su mayor parte de soldados y oficiales, entre gritos e insultos clausuró, clavando grandes tablas, el «Cine Mundial», los establecimientos comerciales de los señores Gerardo Corbacho, Enrique G. Quijano, Carlos 


\subsection{La niñez en Tacna y la resistencia a la campaña chilenizadora:}

Los relatos de Basadre, Vargas Hurtado, Freyre, los hermanos Barreto, entre muchos otros, que relataron su infancia de forma oral y escrita en plena ocupación de Chile en los territorios de Tacna y Arica, todos confluyen, que el éxito de la campaña de resistencia, se debió a los niños y jóvenes, que permitieron las comunicaciones entre los dirigentes de la resistencia y la distribución de panfletos patrióticos. A pesar, que estos se veían directamente afectados a la campaña de adoctrinamiento militar y educativo por parte del estado chileno. Durante 1890 - 1901, las comunicaciones desde el Perú hacia los territorios cautivos eran complejas y tardías; asimismo, el "ojo observador" de la administración chilena, la tenía sobre los más prominentes patriotas de Tacna y Arica. Por lo cual, se apeló a los niños, quienes, entre juegos y mandados a los comercios, repartían los comunicados entre los miembros de las "Sociedades Patrióticas" y "Escuelas Clandestina". Muchas de las versiones que han trascendido a lo largo de los años, se han registrado de forma oral. En el caso particular de Jorge Basadre; quien en su libro "Infancia en Tacna", relata algunos sucesos, debido a que a los cinco años de edad se fue a la capital del Perú; muchos de los hechos que refleja en sus diversas obras, son de "oralidad transcrita". Sin embargo, la obra de Basadre de la campaña Plebiscitaria, son sin duda, los más próximos a los hechos, pues fueron vividos en primera persona. Sobre la infancia en Tacna, los hermanos Barreto romantizan algunos hechos en pro de mantener una actitud identitaria a la causa nacional. Los relatos, sobre los infantes y adolescentes en Tacna, se toman de forma distante en los documentos oficiales generados por la administración chilena. Sin embargo, algunos de los relatos, son dignos de recordar, como los son: la preparación de la Procesión de la Bandera - 28 de Julio 1901. Cabe indicar que el Acta de la Sociedad de Artesanos y Auxilios Mutuos de Tacna, no detalla muchos de los "por menores" que concluyeron con la participación masiva, cívica y solemne de honra a la "Patria distante". Algunos relatos dispersos, cuentan como los niños y adolescentes tacneños aprovechaban sus salidas de recreación para comunicar puerta por puerta o entregando notas de papel a los vecinos de la ciudad. También cabe recordar como algunos jóvenes en franco desafío a la autoridad chilena, izaron la bandera nacional, en el árbol que plantara Bolívar en la Villa de Pachía. Es decir, los niños y jóvenes de la ciudad, fueron la fuerza motriz y movilizadora del mensaje de resistencia y amor a la patria. Como lo describe (Barreto Bustios, "La Procesión de la Bandera", 1921) ${ }^{19}$.

\section{Fotografía $\mathbf{N}^{\circ} 08$}

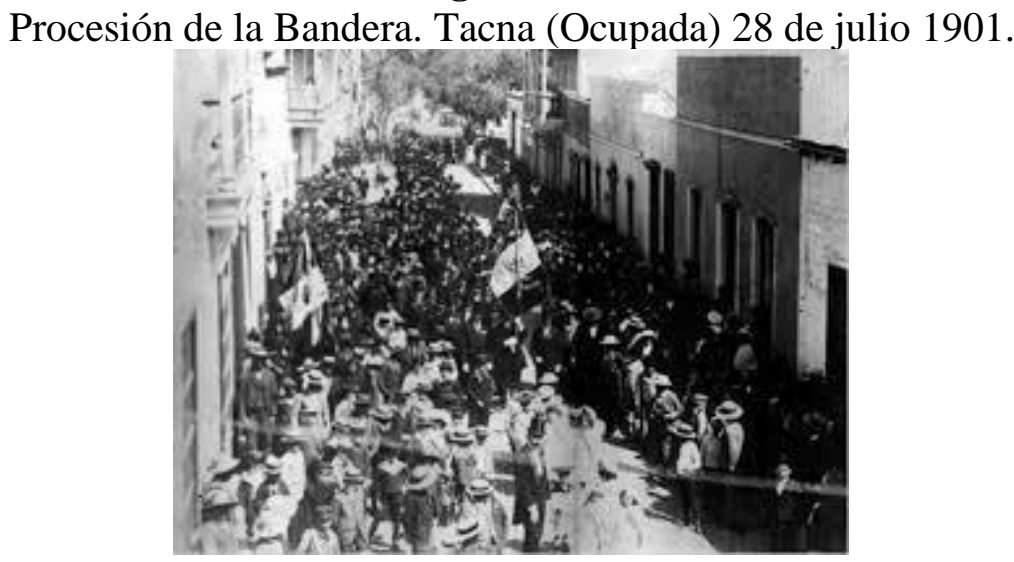

Fotografía: Colección: Sociedad de Auxilios Mutuos “El Porvenir” (1901). "Procesión de la Bandera.

Tacna (Ocupada) 28 de julio 1901. Lugar: Tacna, Perú. Autor de la obra: (Desconocido). Título:

“Procesión de la Bandera. Tacna (Ocupada) 28 de julio 1901”. Imagen tomada de Archivo Regional de

Tacna. Disponible: Archivo Regional de Tacna. [Consulta: 2020, enero, 26].

Céspedes, Guillermo Carlos, Alberto Capellino, Aníbal Marchand, Víctor González y Ghersi Hermanos. Los establecimientos de don Manuel Sologuren, Manuel Liendo, Daniel Crespo, Manuel Yanulaque, Vicencio Tara y Enrique Ward y el Teatro Nacional, de don Juan José Vidal, fueron asaltados y, también, clausurados. Las casas particulares del doctor Carlos Téllez, del ingeniero señor Carlos Valverde, de don Alberto Díaz, del doctor don Luis O. Díaz de don Manuel Belaúnde, fueron apedreadas y clausuradas en la misma forma que los establecimientos de comercio. Es digno de notar que, en esa ocasión, no hubo policía que escoltase a los asaltantes, ni que cuidase el orden público, no obstante que el cuartel de policía apenas dista dos cuadras de las calles en que se efectuaron los sucesos $\{\ldots\} "$.

${ }^{19}$ Véase: Barreto Bustíos, Federico. Revista Variedades, Edición del Centenario de la Independencia, Año XVII, No. 700, Lima, Perú, 30 de julio de 1921. 
Los hechos narrados por Federico Barreto, tienden a romantizar los hechos sobre el cautiverio, esto queda evidenciado en el relato del soldado ex combatiente de la Batalla de Tacna ó del Alto de la Alianza, lo más probable, es que los pocos sobrevivientes de la batalla de Arica y de Tacna; estuvieron presentes en la "Procesión de la Bandera". Sin embargo, también es cierto que muchos ex combatientes luego de la ocupación de Tacna y Arica, una vez desmovilizados y terminado el Tratado de Ancón, fueron exiliados o autoexcluidos - por temor a represalias - en sus hogares, la mayoría de desmovilizados, fueron a vivir a áreas rurales o las áreas liberadas bajo control peruano. El conflicto político reinante entre "pradistas", "pierolistas" y "caceristas" era insalvable hasta en la convivencia de antiguos miembros del ejército peruano. La situación era tan compleja que Modesto Molina. La política y el caudillismo no fue ajeno a jugar sus cartas durante la "lucha por peruanidad" en Tacna y Arica.

Sobre la infancia en el cautiverio, algunos relatos como el de Doña Otilia Soto, nacida en Arica en el año 1905. Narraba que la bandera era escondida en la habitación de sus padres. "Los 28 de julio la tendían en la cama y alrededor de ella cantaban el Himno Nacional. Todo era en secreto. El gobierno chileno de ese entonces había prohibido cualquier manifestación de patriotismo. Estaba en marcha una chilenización". Doña Otilia, que apenas tenía 20 años, decidió cargar la bandera de casa consigo. Se le ocurrió llevarla debajo de su ropa como una especie de vestido. Llevarla en el equipaje era peligroso (Diario La República, 2018). Muchos de los niños expulsados durante la época de la "chilenización violenta", vuelven con la comisión plebiscitaria para el acto de entrega de Tacna, al respecto María Eugenia La Fuente, relata:

"Doña María Eugenia me mira largamente, un vendaval de recuerdos parece haber estallado en su mente, un brillo especial juguetea en sus ojos. Con voz suave, pausada, temblorosa, me dice: "El día 28 muy temprano nos levantamos, nos aseamos y y listas salimos a hacer un rápido recorrido por la ciudad. Algo que me impresionó grandemente y que aún hoy al evocarlo lacera mi corazón de mujer y de peruana: fue el toparme con aquellas cruces negras en muchas de las puertas de los tacneños de entonces, a quienes la horda enemiga había marcado para darles muerte". Y es aquí donde la voz se le quiebra y doña María Eugenia prorrumpe en llanto. Sin duda, el tropel de recuerdos ha sido demasiado fuerte. Mirándome entre vacilante y compungida, me dice: "Perdóneme es la emoción de los recuerdos, es algo que no puedo evitar..." y entre lágrimas como quien eleva una oración, evocando sin duda a los Mártires de Arica, recita estos versos de Federico Barreto: "De mi suelo natal estoy proscrito, / y al verme aquí, tan lejos de mis lares, / la indignación ahoga mis pesares, / y en lugar de una queja, lanzo un grito... " y un blanco pañuelo vuelve a enjugar sus lágrimas “ (Diario Correo, 2013, págs. 05-06).

\subsection{El escultismo en Tacna y su colaboración en la resistencia}

Como antes mencionamos, la aplicación del método scout por parte del gobierno de Chile desde Pedro Montt hasta Carlos Ibañez, utilizaron en los territorios cautivos de Tacna y Arica, como herramienta de adoctrinamiento para "fomentar" la identidad de chilenidad, como mecanismo de desarrollo social y económico, mediante el desarrollo del discurso patriótico - nacionalista chileno y el fomento del adiestramiento militar de forma lúdica, la cual permita una mejor adaptación de los jóvenes para servir al estado chileno. Al respecto, el Decreto Ley $\mathrm{N}^{\circ} 520$ en septiembre de 1925, bajo el mandato del presidente Alessandri. Dándole el título de "Institución Patriótica", haciendo obligatorio su implementación en los liceos del territorio chileno. El 25 de mayo de 1911, el educador Juan Luis Rospligliosi y Gómez Sánchez, funda en el Instituto Ingles de Barranco - Lima, funda el primer grupo scout del Perú. Para el año 1916 el escultismo en el Perú, se diseminó brigadas en Arequipa, Huamachuco, Tayabamba, Paita, Cuzco, Puno, Chincha y el Callao. En Chiclayo las brigadas fueron organizadas por el colegio nacional de San José. En un artículo de 1916 se elogiaba a este movimiento de la siguiente manera: "Era necesaria la implantación entre nosotros del scoutismo, á fin de que nuestros niños se vayan acostumbrando á la disciplina severa y á la obediencia, y los padres á verlos en ejercicios varoniles y á apreciar los beneficios que éstos les reportan y pierdan ese miedo necio y femenino que los hace involuntariamente ser ellos, los padres, los que debían precisamente obligar á sus hijos á servir á la patria, los que, por exceso de cariño, ó porque á ellos no les enseñaron ni les exigieron cumplir, retienen á sus hijos, les apañan y les fomentan que vergonzosa y cobardemente burlen la ley de servicio (militar) obligatorio y defrauden las esperanzas de la patria de contar con ciudadanos que sepan defenderla y hacerla respetar" (Revista Variedades, 1916, pág. 26). El inicio del escultismo en el Perú, coincide con los primeros acercamientos del método scout en las provincias cautivas de Tacna y Arica; al igual que su par chileno, el movimiento scout en el Perú promueve 
los valores, cabe indicar, que muchos expatriados de los territorios ocupados por Chile, participen de las brigadas Scout formadas en el sur del Perú. La relación familiar entre los cautivos y los desplazados a regiones del territorio peruano, sirvió para utilizar el método scout impuesto como mecanismo de resistencia la chilenización. Los relatos históricos orales sobre el accionar de los niños y jóvenes de Tacna para promover la resistencia de la identidad nacional, fue ejecutado en el esquema de patrullas. Los jóvenes establecieron una estructura bien articulada para apoyar las comunicaciones entre la Tacna Libre (distrito de Sama) y las cautivas (Tacna y Arica. Al respecto el Señor Enrique Nalvarte (Nalvarte, 1992) en el año 1992, relataba: “\{...\} El grupo de muchachos que estábamos a cargo de “contrabandear” los diarios peruanos, lo hacíamos por el camino de Tacna a Sama. Lo hacíamos por las noches, en las pampas del campo de batalla. Muchas veces teníamos que cubrirnos entre las quebradas, ya que alguna que otra patrulla de gendarmes patrullaban la zona. Siempre nos íbamos de seis o siete, como nos enseñaban en la escuela ${ }^{20}$. Una vez que llegábamos a Tacna, salíamos de noche a repartir el periódico a escondidas. Los guardábamos entre árboles o en chacras cercanas a Tonchaca (zona agrícola aledaña a la rivera del Río Caramolle). Dejábamos alguna que otra marca para que los otros - referencia a otros jóvenes- pueda llevarlos a Pocollay o Pachía entre las chacras". Este relato es decidor sobre cómo se aplicó el método scout en Tacna \{...\}." (Nalvarte, 1992).

\section{CONCLUSIONES}

Por medio de las diversas fuentes documentales y orales, el rol del escultismo como herramienta de adoctrinamiento por parte del aparataje del estado chileno en relación al tema de Tacna y Arica. Sin embargo, la utilidad del método scout en Tacna, sirvió para dar soporte a la resistencia a la campaña de chilenización impuesta entre 1880 a 1929. La derrota diplomática del Perú, pese a contar con el apoyo del Gobierno de Estados Unidos, que fue abiertamente pro peruano, se vio debilitado por las circunstancias que aquejaron al oncenio de Leguía en el contexto de nuevos frentes de conflicto territorial ${ }^{21}$. La falta de unidad debido al caudillismo entre 1880 - 1915, debilitó una postura nacional más eficiente en cuanto al tema de Tacna y Arica. Chile impuso sus condiciones del ámbito militar y material. El Perú, poco o nada podía hacer con la crisis que degeneró la guerra del Pacifico. El único bastión de resistencia era la educación clandestina como refiere (BASADRE GROHMANN, "Infancia en Tacna", 1959), Doña María Eugenia La Fuente (Diario Correo, 2013) y (Llanos E. , 2018). Como refiere (CASTRO OYANGUREN, 1919) El periodo denominado la "Chilenización pacífica" tenía una clara estrategia entre 1880-1884, que era la convivencia era pacífica y armónica. Esta estrategia no debilitaba la identidad nacional de los pobladores de Tacna y Arica; quienes aún se sentían peruanos y promovían en las escuelas peruanas de los territorios ocupados la identidad patria peruana. Entre los años 1887-1915, ejecuta ingentes cantidades de dinero en las provincias cautivas, en obras de infraestructura pública, entre ellas escuelas. Remitiendo de la capital chilena, los mejores pedagogos de la época. La instauración del método educativo Scout dentro de la educación pública obligatoria de Chile, trató de llevar la militarización de la juventud. Por tanto, el Fundador del Movimiento Baden Powell, aclaró el panorama en su discurso ante las autoridades chilenas como señala (DEL BRUTO, 2016) de que el movimiento, se basaba en educar, formar y guiar a los jóvenes para servir a su patria, pero con una consigna de paz e integración. En tal sentido, el aparataje cívico militar con que utilizó el método Scout el gobierno de Chile, fue de adoctrinamiento, como el utilizado por los gobiernos fascistas de Hitler y Musolini en Europa en la década del 30’. Sin embargo, la estrategia ideológica formada por Samuel A. Lillo y Phillips - ambos ex combatientes del 79' y encargados de la administración política - militar en Tacna y Arica durante el desarrollo de la guerra entre Chile y Perú llevó a entender, que el medio más eficaz de sometimiento y cambio de identidad de los niños y jóvenes de las provincias cautivas y territorios ocupados, se basaba por medio de la educación y el influjo de la identidad chilena sobre el pasado peruano de estas comunidades. Durante este proceso de erradicación de la peruanidad, los niños, jóvenes y maestras, aprovecharon esos mismos medios impuestos por el gobierno chileno para reorganizar, revitalizar y dar sostenibilidad a la resistencia de identidad peruana en los territorios de Tacna y Arica, haciendo posible la comunicación entre escuelas clandestinas y los territorios liberados de soberanía peruana. El proceso de cautiverio entre 1880 y 1929, fue cruento y traumático en el

\footnotetext{
${ }^{20}$ Ref. Sistema de patrullas, establecido por el método scout. El cual fue implementado por el gobierno chileno y la administración civil y militar de los territorios ocupados.

${ }^{21}$ Conflicto Peruano - colombiano,
} 
sentimiento nacional peruano; y al mismo tiempo de reafirmación de la identidad nacional peruana como refieren (Telles, 1925), (CASTRO OYANGUREN, 1919) y (FERNANDEZ VALDIVIA, 2004).

\section{BIBLIOGRAFÍA}

Academia de Historia Militar de Chile. (2014). "Fuerzas Militares chilenas en Tacna y Arica". Academia Histórica Militar de Chile, 39-40.

Amoros, M. (2014). Allende. La Biografia. En M. Amorós, Allende. La Biografia (págs. 100-110).

Santiago: Penguin Random House Grupo Editorial Chile.

Arancibia Floody, C. (2014-2016). La Presencia del Ejército de Chile durante la ocupación de Tacna y

Arica (1880-1929). Anuario de la Academia de Historia Militar - Chile(48), 45-49.

Arriagada Aljaro, E. (2010). "La participación del Ejercito de Chile en las festividades del Centenario

Nacional". Anuario de la Académia de Historia Militar de Chile, 24, 08-136. Obtenido de

http://www.academiahistoriamilitar.cl/academia/wp-content/uploads/2018/04/anuario24.pdf

BADEN POWEL OF GILWEL, R. S. (1908). "Escultismo para muchachos" (12 ed.). Gilwell, Reino

Unido: Horace Cox. Recuperado el noviembre de 2020, de

https://www.academia.edu/16297309/Escultismo_para_muchachos_BP

Barreto, J. (1919). El problema peruano-chileno. Imprenta Americana.

BASADRE GROHMANN, J. (1959). "Infancia en Tacna". En J. Basadre Grohmann, "Infancia en Tacna (pág. 95). Tacna: Villanueva.

BASADRE GROHMANN, J. (1975). "La Vida y la historia: ensayos sobre personas, lugares y

problemas" (Segunda ed.). Lima, Peru: Industrial Gráfica.

Castillo Valderas, C. (2012). "EL ESTADO CHILENO Y LA CONSTRUCCIÓN DE LA IDENTIDAD

NACIONAL: LA CONTROVERSIA POR TACNA Y ARICA (1883-1929)”. 41-50. Valdivia, Chile.

Obtenido de http://cybertesis.uach.cl/tesis/uach/2012/ffc352e/doc/ffc352e.pdf

CASTRO OYANGUREN, E. (1919). "Entre el Perú y Chile: la cuestión de Tacna y Arica Páginas de

divulgación histórica". Lima, Perú: Imprenta Estado.

COX MÉNDEZ, R. (1944). "Recuerdos de 1891". Santiago: 197 - 230.

Cruchaga Torconal, M. (1927). Conferencia Panamericana. Revista Chilena, 15-20.

Cruz-Coke M., R. (2003). Sintesis siografica del doctor Salvador Allende. Revista Medica de Chile,

131(7), 809-814. doi:http://dx.doi.org/10.4067/S0034-98872003000700014

Dager Alva, J. \&. (2005). EL DIOS CAUTIVO. LAS LIGAS PATRIÓTICAS EN LA

CHILENIZACIÓN COMPULSIVA DE TARAPACÁ (1910-1922). Si Somos Americanos, Revista de

Estudios Transfronterizos, VII(02), 199-209. Obtenido de https://www.redalyc.org/pdf/3379

Dager Alva, J. \&. (2005). EL DIOS CAUTIVO. LAS LIGAS PATRIÓTICAS EN LA

CHILENIZACIÓN COMPULSIVA DE TARAPACÁ (1910-1922). Si Somos Americanos, Revista de

Estudios Transfronterizos,, VII(02), 199-209. Obtenido de https://www.redalyc.org/pdf/3379

DEL BRUTO, A. (2016). Una mirada a 100 años. Breve reseña histórica de Guías y Scouts de Chile. En

A. Del Brutto. Santiago: Asociaciónde Guías y Scouts de Chile, Comisión Proyecto Educativo

Institucional.

del Brutto, A. (2016). Una mirada a 100 años. Breve reseña histórica de Guías y Scouts de Chile. En A.

Del Brutto. Santiago: Asociaciónde Guías y Scouts de Chile, Comisión Proyecto Educativo Institucional.

Diario Correo. (28 de agosto de 2013). "Las maestras peruanas durante y después del cautiverio". "Las

maestras peruanas durante y después del cautiverio", págs. 05-06.

Diario El Ferrocarril. (04 de agosto de 1920). "El aeroplano Arica". "El aeroplano Arica", pág. 03.

Diario El Ferrocarril. (06 de agosto de 1920). "Instrucción Militar a la Brigada de Boy Scouts Arica".

"Instrucción Militar a la Brigada de Boy Scouts Arica", pág. 7.

Diario El Ferrocarril. (27 de julio de 1925). "Ayer llegó a este puerto la Delegación que preside el señor Edwards". "Ayer llegó a este puerto la Delegación que preside el señor Edwards", pág. 03.

Diario El Ferrocarril. (22 de agosto de 1925). "El Gran Desfile Patriótico de mañana". "El Gran Desfile Patriótico de mañana", pág. 02.

Diario El Ferrocarril. (25 de agosto de 1925). "La manifestación que se realizó ayer en Arica". " $L a$

manifestación que se realizó ayer en Arica”, pág. 03. 
Diario El Ferrocarril. (05 de abril de 1926). "El eterno ridículo". "El eterno ridículo”, pág. 03.

Diario El Ferrocarril. (19 de octubre de 1927). "El Ministro de Guerra llegó hoy a Arica". "El Ministro de Guerra llegó hoy a Arica”, pág. 05.

Diario El Ferrocarril. (06 de julio de 1927). "Festejos al Ministro de Relaciones y su comitiva". "Festejos al Ministro de Relaciones y su comitiva”, pág. 02.

Diario El Mercurio. (18 de septiembre de 1910). "Los programas de hoy". "Los programas de hoy", pág. 23.

Diario El Pacífico. (05 de marzo de 1910). "Expulsión de los peruanos". "Expulsión de los peruanos", págs. 3-4.

Diario El Pacífico. (8 de marzo de 1910). "Servicio Militar de los tacneños” . "Servicio Militar de los tacneños”, págs. 03-04.

Diario La República. (28 de agosto de 2018). "Tacna: la bandera que resistió a la época del cautiverio chileno" . "Tacna: la bandera que resistió a la época del cautiverio chileno" , págs. 05-06.

El Ferrocarril. (5 de abril de 1926). El Eterno Ridiculo. El Eterno Ridiculo, págs. 3-4.

El Mercurio. (26-27 de mayo de 1909). Exposición de Baden Powell.

El Mercurio. (15-16 de setiembre de 1910). Actividades Scout. El Mercurio.

El Scout. Siempre listo. (7 de junio de 1914). Discurso de orden a la gesta de Arica. El Scout. Siempre Listo, 3-4.

El Scout. Siempre Listos. (mayo de 1920). Decimo primer aniversario de Escultismo en Chile. El Scout. Siempre Listos(9), 6-7.

FERNANDEZ VALDEZ, J. C. (2004). "Chile y Perú. Historia de sus relaciones diplomáticas entre 1879 y 1929". Santiago: RIL Editores.

FERNANDEZ VALDIVIA, J. J. (2004). "CHILE Y PERÚ: Historia de sus relaciones diplomáticas entre 1879 - 1929". Santiago, Chile: Ril editores.

GONZALEZ, S. (2002). Chilenizando a Tunupa: La escuela publica en el Tarapaca andino (188019900). Santiago: Dirección de Bibliotecas, Archivos y Museos, Centro Barros Arana.

Llanos, \& Nelson, e. a. (2011). EL REINO CHILENO DEL TERROR: LA PRENSA

ESTADOUNIDENSE Y LA CONTROVERSIA DE TACNA Y ARICA, 1925-1926. Revista: Estudios

Hemisféricos y Polares, 02(02), 56-59.

Llanos, E. (2018). "La ciudadanía como conexión política entre las identidades en el Perú". Anales

Científicos, 79(01), 13-20. doi:DOI: http://dx.doi.org/10.21704/ac.v79i1.1134

Molinarie, N. (1912). Semanario Ilustrado La Patria. En N. Molinare, La Patria (pág. 24). Santiago: La Patria.

Montenegro, E. (1919). La cuestion chileno-peruana: Exposicion de hechos,. Santiago, Chile.

MUÑOZ FIGUEROA. (1914). "El problema de nuestra educación militar” . En MUÑOZ FIGUEROA,

"El problema de nuestra educación militar” (págs. 20-30). Santiago: Académia de Historia Militar del Ejercito de Chile.

Nalvarte, E. (26 de mayo de 1992). "Su infancia en la ocupación de Tacna". (A. Luna, Entrevistador)

Nieto del Rio, F. (1927). Tacna y Arica. Revista Chilena(XI), 86-87. Obtenido de

http://www.memoriachilena.gob.cl/archivos2/pdfs/MC0070715.pdf

Palacios , R. (1973). Tacna y Arica 1883-1929: notas en torno a la historia de la Chilenizacion. Revista

PUCP.

PALACIOS, R. (1974). La chilenización de Tacna y Arica 1883-1929. Lima: Arica.

Pizarro, A. (2003). "Mitos y construcción del imaginario nacional cotidiano". Atenea(483), 103-111.

doi:https://dx.doi.org/10.4067/S0718-04622003048700008

PORTOCARRERO, G., \& KOMADIMA, J. (2001). "Nuevos modelos de identidad en la sociedad peruana, Transformaciones sociales y nuevos sentidos de pertenencia en Bolivia". Lima, Lima, Perú:

Instituto de Estudios Peruanos (IEP). Recuperado el noviembre de 2020, de http://catalogo.iep.org.pe/cgibin/koha/opac-detail.pl?biblionumber $=3262$

Revista "Dichos y Hechos. (27 de diciembre de 1913). Maniobras del movimiento scout de Chile. 6. Revista Católica. (10 de junio de 1914 ). Ceremonia de bendicion del estandarte de las brigadas juveniles Arica 07 de Junio 1974. Revista Catolica, 10-12.

Revista Chilena. (1927). Tacna y Arica. Revista Chilena, 88-97. 
Revista Variedades. (20 de junio de 1916). "El movimiento Scout en el Perú". "El movimiento Scout en el Perú", pág. 26.

Revista Zig Zag. (10 de abril de 1910). "La cripta de los héroes en Tacna". "La cripta de los héroes en Tacna", págs. 08-10.

Rojas Flores, J. (2004). Moral y prácticas cívicas en los niños chilenos, 1880-1950. En Moral y prácticas cívicas en los niños chilenos, 1880-1950. (págs. 81-82). Santiago: Ariadna.

ROJAS FLORES, J. (2006). "Los Boy Scout en Chile 1909 - 1953". Santiago: Centro de Investigaciones Diego Barros Arana.

Rojas Flores, J. (2006). "Los Boy Scout en Chile" 1909 - 1953. Santiago: Centro de Investigaciones Diego Barros Arana.

Roosevelt , T. (18 de Noviembre de 1913). "Declaracíon sobre el "Huáscar". "Declaracíon sobre el "Huáscar". Valpariso, Chile.

Ruz, E., \& et al. (2015). “Alterización del Perú Negro en Magazines Chilenos: Corre-Vuela 1910-1930”.

Ciencia y Tecnología de América, 40(11), 799-806. Obtenido de https://www.interciencia.net/wpcontent/uploads/2017/10/799E-RUZ-ZAGAL7color-VOL.-40_11.pdf

Serra Anguita, D. (julio - diciembre de 2015). ¿Celebrar o no celebrar? La Organiación de los festejos oficiales del centenario de la independencia de Chile 1904-1910". Historia, 2(48), 595-626. Recuperado el noviembre de 2020, de https://scielo.conicyt.cl/pdf/historia/v48n2/art07.pdf

Sierra, M. N. (julio - septimebre de 2013). LA DOCTRINA MONROE ESTÁ MÁS VIVA QUE

NUNCA. THEODORE ROOSEVELT, CHILE, Y LAS RELACIONES INTERAMERICANAS UN

SIGLO ATRÁS. Hemisferic and Polar Studies, 4(3), 244-266. Obtenido de www.hemisfericosypolares.cl Soto Correo , J., \& et al. (2017). La flor de lis en el erial: Impronta masónica sobre los scouts de Arica (Chile, 1912-1929). Revista de Estudios Históricos de la Masonería Latinoamericana y Caribeña, 9(1), 76-104. doi:10.15517/rehmlac.v9i1.28109

Telles, C. (1925). La cuestión de Tacna y Arica. Editorial Cervantes, 5.

TRELLEZ, C. (1925). La cuestion de Tacna y Arica. Lima: Cervantes.

Tupper Leon, P. (1979). El comandante Enrique Phillips Huneeus Creador del primer Museo Militar y temprano impulsor de la aviación (1859-1939). En P. Tupper Leon, El comandante Enrique Phillips

Huneeus Creador del primer Museo Militar y temprano impulsor de la aviación (1859-1939) (págs. 76-

85). Santiago: Anuario Academia de Historia Militar de Chile.

VARAS OLEA, C. (1921). Tacna y Arica bajo administracion chilena. Santiago.

Vera Yannatiz, A. (1924). Labor educacional chilena en Arica. En Labor educacional chilena en Arica. Vicherat, A. (27 de agosto de 1965). "Su compañero Salvador Allende".

Yepes, E. (1999). Un Plebicito Imposible: Tacna y Arica 1925-1926: (Informe Pershing y Lassiter). En E. Yepes, Un Plebicito Imposible: Tacna y Arica 1925-1926: (Informe Pershing y Lassiter). Lima: Analisis. Zagal, R. \&. (2018). LA COMISIÓN PLEBISCITARIA TACNA-ARICA A TRAVÉS DE LAS CARICATURAS DE LA REVISTA SUCESOS (1925-1926. Historia, 396(8). Obtenido de https://www.researchgate.net/publication/326232225_LA_COMISION_PLEBISCITARIA_TACNAARICA_A_TRAVES_DE_LAS_CARICATURAS_DE_LA_REVISTA_SUCESOS_19251926/citation/download Zañartu , D. (12-15 de septiembre de 1913). Escultismo en Chile. 12-15. 